\title{
Monitoring Environmental Change Using Inuit Qaujimajatuqanjit in Cape Dorset, Nunavut.
}

\author{
By \\ Anita Kushwaha, BSc. (Honours) \\ A thesis to the Faculty of \\ Graduate Studies and Research in partial fulfillment \\ Of the requirements for the degree of \\ Masters of Arts \\ Department of Geography and Environmental Studies
Carleton University
Ottawa, Ontario 2007 \\ (C) Copyright 2007 \\ Anita Kushwaha
}




$\begin{array}{ll}\begin{array}{l}\text { Library and } \\ \text { Archives Canada }\end{array} & \begin{array}{l}\text { Bibliothèque et } \\ \text { Archives Canada }\end{array} \\ \begin{array}{l}\text { Published Heritage } \\ \text { Branch }\end{array} & \begin{array}{l}\text { Direction du } \\ \text { Patrimoine de l'édition }\end{array} \\ \begin{array}{l}\text { 395 Wellington Street } \\ \text { Ottawa ON K1A ON4 }\end{array} & \begin{array}{l}\text { 395, rue Wellington } \\ \text { Ottawa ON K1A ON4 } \\ \text { Canada }\end{array}\end{array}$

Your file Votre référence ISBN: 978-0-494-33746-2 Our file Notre référence ISBN: 978-0-494-33746-2

NOTICE:

The author has granted a nonexclusive license allowing Library and Archives Canada to reproduce, publish, archive, preserve, conserve, communicate to the public by telecommunication or on the Internet, loan, distribute and sell theses worldwide, for commercial or noncommercial purposes, in microform, paper, electronic and/or any other formats.

The author retains copyright ownership and moral rights in this thesis. Neither the thesis nor substantial extracts from it may be printed or otherwise reproduced without the author's permission.
AVIS:

L'auteur a accordé une licence non exclusive permettant à la Bibliothèque et Archives Canada de reproduire, publier, archiver, sauvegarder, conserver, transmettre au public par télécommunication ou par l'Internet, prêter, distribuer et vendre des thèses partout dans le monde, à des fins commerciales ou autres, sur support microforme, papier, électronique et/ou autres formats.

L'auteur conserve la propriété du droit d'auteur et des droits moraux qui protège cette thèse. $\mathrm{Ni}$ la thèse ni des extraits substantiels de celle-ci ne doivent être imprimés ou autrement reproduits sans son autorisation.
In compliance with the Canadian

Privacy Act some supporting forms may have been removed from this thesis.

While these forms may be included in the document page count, their removal does not represent any loss of content from the thesis.
Conformément à la loi canadienne sur la protection de la vie privée, quelques formulaires secondaires ont été enlevés de cette thèse.

Bien que ces formulaires aient inclus dans la pagination, il n'y aura aucun contenu manquant.

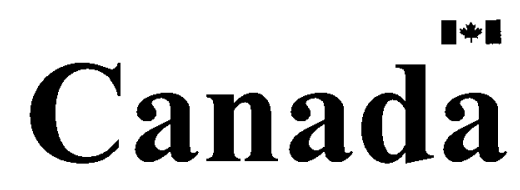




\begin{abstract}
Inuit in the Canadian Arctic have generations of experience traveling, hunting and living in close relationship with the land. The land is critical to the health and wellbeing of Inuit. Connections to the land go far beyond the physical, but rather extend into the spiritual, emotional, social and cultural realms of health and wellbeing. Inuit are witnessing dramatic changes in the Arctic environment upon which they depend. As the characteristics of the land change, so too will the relationship of Inuit with the land. Understanding the relationship between health and the land in the context of environmental change is poorly understood. However, the implications of environmental change for Inuit physical, emotional, spiritual and cultural health are significant. Monitoring culturally significant aspects of the environment, such as sea ice and the health of ringed seals, provides a greater understanding of the role that the land plays in Inuit health and wellbeing.
\end{abstract}




\section{Dedication}

I dedicate this work to the memory of Akalayok Qauvavau (1955-2006). From the moment we met, you treated me with warmth and respect. I have never worked with anyone who was more passionate than you. Without your support, my experience in Cape Dorset would have been very different. Thank you for teaching me about the community of Cape Dorset. Thank you for teaching me about life in the North and what it means to be an Inuk. Thank you for taking me on the land, sharing tea with me, and making me feel like a part of your family. I still wear the $u l u$ pendant you gave me and remember fondly how you told me that now I was a "real woman". It is difficult for me to imagine a Cape Dorset without you, but I will always cherish the time we had. I am so very grateful to have met you. 


\section{Acknowledgements}

I would first like to thank my supervisor, Dr. Nancy C. Doubleday, for the guidance and support she has provided me over the last two years. I am so grateful to her for allowing me the freedom to discover and develop my research interests. I've learned many valuable lessons that will no doubt shape the way I approach research in the future.

I would also like to thank Shawn Donaldson for always being available to brainstorm ideas or troubleshoot a problem. You've been a great mentor.

I would like to thank the Community of Cape Dorset who has made this research possible. Traveling and working in the North has forever changed the way I look at the world. Thank you to all the participants, and to my interpreters, Pootoogoo Elee and Silaqqi Alariaq, for taking the time to share their stories with me.

A huge part of my support system over the last two years has come from the fellow Master's students I have met in the Geography department. Thanks to Sarah and Kwesi for the all the lunch dates at Mike's place. A huge thanks goes to my friend Rae-lyn, for being such a wonderful friend and listening to me when I needed to vent.

I would like to thank my family for being a source of constant inspiration and support for me throughout this journey. To my Mom and Dad, thank you for always encouraging me to get a quality education, and for believing in me. To my big brother Nim, thank you for trying to ease my burdens any way you could, whether it was treating me to lunch or listening to my worries during a late night phone call. To my big sister Neena, thank you for being a great example to look up to. You helped me to see that no matter the situation, there is always a way forward. To my brother-in-law Mike, thank you for all the great discussions and for challenging me to question why I believe the things that I do. To my cat Noodles, even though you can't read I must thank you for all the cuddles. I love you all more than I can say.

To the love of my life, Daniel Thakorlal, thank you for the endless support and love you have given me. You have been my inner strength when I felt that I had none left. Thank you for always being interested in my work and for wanting to be included. Thank you for never thinking twice about listening to a presentation or proof-reading a paper. Thank you for the endless cups of tea and for all the laughter you bring to my life. I could not have taken on this challenge without you by my side. You are the Sun and the Moon to me. I am so happy to be traveling along this journey of life with you. 


\section{Table of Contents}

$\begin{array}{lc}\text { Abstract } & \text { i } \\ \text { Dedication } & \text { ii } \\ \text { Acknowledgements } & \text { iii } \\ \text { List of Tables } & \text { vii } \\ \text { List of Appendices } & \text { viii }\end{array}$

Chapter 1 - Introduction

1.1. Introduction 1

1.2. Statement of the Problem 5

1.3. Research Objectives 5

1.4. Thesis Organization $\quad 6$

Chapter 2 - Literature Review

2.1. Therapeutic Landscapes: An Examination of Health and Place in the Context of Environmental Change $\quad 7$

2.2. Importance of Traditional Foods to the Health and Wellbeing of Inuit $\quad 10$

2.3. The Importance of Seal to Inuit Health and Wellbeing 14

2.4. Defining Traditional Ecological Knowledge 17

2.4.1. Distinguishing Inuit Qaujimajatuqanjit from TEK 22

2.5. Using Traditional Ecological Knowledge to Monitor Environmental Change 23

2.6. Inuit Observations of Changes to Ringed Seal Health 26

2.7. Sea Ice as an Important Substrate for Ringed Seals 27

2.8. Body Condition as a Measure of Environmental Stress 29 
Chapter 3 - Research Approach and Methods

3.1. Research Approach

3.11. Participatory Action Research 32

3.1.2. Community-based Traditional Knowledge Research 34

3.2. Methods 38

$\begin{array}{ll}\text { 3.2.1. Study area } & 38\end{array}$

3.3. Data Collection 39

$\begin{array}{ll}\text { 3.3.1. Interviews } & 39\end{array}$

3.3.2. Community-based Monitoring of Ringed Seal 40

3.4. Analysis 42

Chapter 4 - Results

4.1. Inuit Observations of Environmental Change in Cape Dorset, Nunavut 44

4.2. Changes in Sea Ice Conditions 44

4.3. Changes in Weather Patterns 46

4.3.1. Temperature 46

4.3.2. Rainfall 47

4.3.3. Wind patterns 48

4.3.4. Snow 48

4.4. Inuit Observations of Ringed Seal 49

4.4.1. Characteristics of Healthy Ringed Seal 50

4.4.2. Benefits of Ringed Seal to Inuit Physical, Emotional, Social and Cultural Health 51

4.4.3. Changes in Ringed Seal Health 54 
Chapter 5 - Results

5.1. Impacts and Adaptation in Response to Environmental Change in Cape Dorset, Nunavut

5.2. Impacts of Changes in Weather on Lifestyle

5.3. Impacts of Changes to Sea Ice on Livelihoods

5.4. Impacts of Changes in Sea Ice and Weather on Ringed Seal 64

5.5. Coping with Recent Environmental Changes Through Adaptation 66

5.6. Local Perspectives of Recent Environmental Change 68

Chapter 6-Discussion

6.1. The Direct and Indirect Impacts of Environmental Change on Human and Environmental Health in Cape Dorset, Nunavut

6.2. The Importance of Examining Health and Place in the Context of Environmental Change

6.3. Coping with the Impacts of Environmental Change

6.4. The Importance of Local Perspectives in the Study of Health and Place in the Context of Environmental Change

Chapter 7 - Summary and Conclusions

7.1. Summary and Conclusions 


\section{List of Tables}

Table 3.1. Five convergence areas that can facilitate the use of traditional knowledge and western science in the context of Arctic environmental change 


\section{List of Appendices}

Appendix A: Community-based Monitoring of Ringed Seal in Cape Dorset, Nunavut: Lessons Learned 103

Appendix B: Ethics Proposal and Interview Guide 107 


\section{Chapter 1}

\section{Introduction}

\subsection{Introduction}

Inuit in the Canadian Arctic have generations of experience travelling, hunting and living in close relationship with the land, and have developed an intimate knowledge of their environment. For ancestral Inuit, having an acute awareness of one's environment was critical to survival. Present day Inuit face challenges similar to those of their ancestors, although the overall complexity of conditions has increased and the forces for change are novel. The land, as place, is critical to the health and wellbeing of Inuit. Inuit connections to the land go far beyond the physical, but rather extend into the spiritual, emotional, social and cultural. The environment has always been a source of livelihood and basis of culture for Inuit (Cobb et al., 2005 in: Berkes et al., 2005). In the modern world, the land continues to be vitally important in the mixed economy of Inuit. In addition, connection with the land helps to maintain Inuit social identity and provides a source of social and cultural values, such as sharing and respect for wildlife.

A growing body of evidence suggests that the Arctic environment is undergoing significant changes (ACIA, 2005). Environmental changes observed in the Arctic during the last decade include increases in average air and ocean temperatures, widespread melting of snow and ice, and rising global average sea level (IPCC, 2007). While environmental change in the Arctic is nothing new, the rate and extent of change has accelerated. Many Inuit communities in the Canadian Arctic are observing environmental changes that differ from normal variability, and which in some cases, go beyond living 
memory. Northern residents are experiencing the effects of climate change in their communities and hunting grounds, and these environmental changes are impacting Inuit livelihoods in a number of ways.

Environmental change, detected through local observations and traditional knowledge has been shown to enrich the understanding of Arctic climate change. Scientific understanding of Arctic environmental and climate change is based on records that are often short-term and fragmentary. In contrast, Inuit have been observing, experiencing, accumulating and communicating knowledge about the Arctic environment for millennia. The use of Inuit Qaujimajatuqanjit or IQ (i.e. Inuit observations and traditional knowledge) is gaining recognition in helping to understand the complexities of Arctic environmental change, particularly at the local-scale. A growing number of studies have documented IQ about the impacts of climate change on caribou and calving grounds (Ferguson et al., 1997; Thorpe, 2000), sea ice (Nichols et al., 2004), permafrost, weather, fish and other wildlife (Riedlinger and Berkes, 2001). This expanding area of research demonstrates the significant contribution IQ has made to the study of Arctic climate and environmental change, particularly in addressing knowledge gaps, while involving local people in research that directly impacts their way of life.

The Arctic region is vulnerable to the impacts of climate change, as is the health and wellbeing of the Inuit that live there. Of the numerous environmental changes being observed in the Arctic today, declines in the thickness and extent of sea ice may have some of the most dramatic impacts on Inuit livelihoods. Sea ice is an important substrate for Inuit, and is a defining feature of the Arctic environment. Being able to safely travel, hunt and spend time in the outdoors while on the ice is an important part of Inuit daily 
life and identity. It is by participating in traditional activities on the land, such as hunting and fishing that IQ is passed along and traditions maintained. Inuit observations of recent changes to the thickness and extent of sea ice have already been documented in communities spanning the Canadian Arctic. As a result, local residents have become increasingly concerned about safety when hunting and travelling on sea ice. In addition to these local observations, global climate models continue to predict substantial decreases in both coverage and thickness of Arctic sea ice in response to climate warming (Manabe et al., 1992). Comiso (2003) suggested that if accelerated warming of the Arctic continues, by 2050, except for the most northerly parts of the Canadian Arctic Archipelago and Greenland, the average minimum extent of sea ice will be several hundred kilometres north of the continental coastlines.

The implications of changes in sea ice to the health and wellbeing of Inuit communities are significant in terms of maintaining traditional activities, such as travelling and hunting on the ice, and access to traditional food sources. Seal, in particular, is an important component of the Inuit concept of physical, emotional and cultural health and wellbeing. Seal is considered "real food" imbued with the power to maintain health through nourishment of the body and soul (Borre, 1994). The ringed seal (Phoca hispida), may be particularly vulnerable to changes in the extent and/or concentration of Arctic ice because they depend on sea ice habitat for pupping, foraging, moulting and resting (Tynan et al., 1997; Derocher et al., 2004; Ferguson et al, 2005). A warmer northern climate will result in less sea ice, fewer ice edges and fewer suitable habitats for ringed seals to occupy. 
It has been suggested that ringed seal populations represent useful indicators of ecological change in northern ecosystems, because of their dependence upon annual sea ice, which has already undergone significant changes in annual cycles of distribution and abundance, and significant further reduction is predicted (Ferguson et al., 2005; Comiso, 2003). The effects of reductions in sea ice on ringed seals are likely to be reflected initially by shifts in range and distribution (Tynan et al., 1997; Ferguson et al., 2005). Demographic changes associated with shifts in geographic range will likely be observed as decreased recruitment in areas of reduced sea ice (Ferguson et al., 2005).

Reduced country food consumption in northern Aboriginal populations has been associated with decreased physical activity, obesity, dental caries, anaemia, lowered resistance to infection, and diabetes (Berkes et al., 2005). However, the importance of subsistence harvesting to human health goes beyond the physical. Contemporary definitions of good health promoted by the World Health Organization (WHO) and other health bodies have been broadened to include a greater sense of well-being (WHO, 1946). Good health entails not only the physical being or the absence of disease, but also includes mental, emotional, and spiritual dimensions. Hunting, fishing and gathering are deeply rooted sources of identity in all of the native cultures, but just as important are sharing and trading (AMAP, 2003). They represent ways to establish and maintain family and community ties, as well as ties between communities. It follows that changes in the health, distribution and availability of important traditional food sources, such as the ringed seal, may put Inuit physical, emotional and spiritual health at risk. 


\subsection{Statement of the Problem}

Inuit are witnessing firsthand changes in the Arctic environment upon which they depend. Inevitably, as the characteristics of the land change so too will the relationship of Inuit with the land and its resources. Understanding the relationship between health and the land, as place, in the context of environmental change is poorly understood. However, the implications of environmental change for Inuit physical, emotional, spiritual and cultural health and wellbeing are significant, particularly in terms of safety when travelling and hunting on the land, and food security (Furgal, 2002 in Krupnik and Jolly, 2002). By monitoring culturally significant aspects of the environment, such as sea ice and the health of ringed seals, it may be possible to gain a greater understanding of the role that the land plays in the health and wellbeing of Inuit.

\subsection{Research Objective}

The goal of this study is to document Inuit observations of environmental change in Cape Dorset, Nunavut. The objective of the study is to:

1) Document Inuit Qaujimajatuqanjit regarding the effects of environmental change on sea ice and ringed seal health, in order to gain a deeper understanding of how environmental change impacts the health and wellbeing of local residents, and their relationship to the land. 


\subsection{Thesis Organization}

This thesis is presented in seven chapters. Chapter 1 provides an introduction to recent Arctic environmental change, and the implications for the health and wellbeing of Inuit in the Canadian Arctic. Chapter 1 also contains the statement of the research problem, the goal of the research, and the research objectives. Chapter 2 presents the theoretical framework and relevant literature which the thesis draws upon. Chapter 3 presents the research approach and methods. Chapter 4 and 5 present the major research results. Chapter 4 summarizes the local observations of environmental change made by residents of Cape Dorset, Nunavut. Chapter 5 summarizes the impacts of recent environmental change on the livelihoods of Cape Dorset residents, and presents the adaptive strategies that they have developed in response to change. Chapter 6 provides a discussion of the importance of studying health and the land, as place, in the context of environmental change. This is followed by a discussion of the direct and indirect impact mechanisms of environmental change on human and environmental health in the Cape Dorset. The various coping strategies which the residents of Cape Dorset have developed in response to environmental change are elaborated upon. The chapter ends with a discussion of the importance of including community-based perspectives when studying the impacts of environmental change on human health. Chapter 7 presents a brief summary of the research findings and outlines the major conclusions. The chapter concludes by highlights future research directions. Chapter 7 is followed by the references and appendices. 


\section{Chapter 2}

\section{Literature Review}

\subsection{Therapeutic Landscapes: An Examination of Health and Place in the Context of Environmental Change}

This chapter begins with an introduction to the concept of therapeutic landscapes, and its application as a theoretical framework for studying the relationship between health and place in the context of environmental change. The study of therapeutic landscapes is a relatively new area of investigation within contemporary Health Geography, which explores the link between health and place. The term therapeutic landscapes, was first introduced by Gesler in 1991, as places with "an enduring reputation for achieving physical, mental, and spiritual health" (Gesler, 1993: 171 in Wilson, 2003). Years later Gesler expanded the definition to landscapes where the "physical and built environments, social conditions, and human perceptions combine to produce an atmosphere which is conducive to healing" in the broadest sense (Gesler, 1996: 96). The term healing is used here in a broad manner to include cures in the biomedical sense (i.e. physical healing), a sense of psychological wellbeing (mental healing) and feelings of spiritual renewal (spiritual healing). Certain places achieve a reputation as healing places. The factors which contribute to this reputation are unique to each place, but include such things as natural and human-made environments, historical events, cultural beliefs, social relations and personal experiences (Gesler, 1996).

The use of therapeutic landscapes in the study of health and place is important because it provides researchers with an alternative way of viewing the link between health and place. It allows researchers to move beyond traditional approaches to place 
and space by embracing more meaningful perspectives that view places as symbolic systems of healing (Wilson, 2003). The study of therapeutic landscapes has generally focused on exceptional places-places of pilgrimage, therapy, and treatment, like holy places, baths, spas, and hospitals (Wakefield and McMullan, 2005). That is to say, the conceptualization of therapeutic landscapes has primarily focused on physical and/or spiritual locations of healing. In doing so, the majority of the research conducted on therapeutic landscapes has overlooked the culturally specific dimensions of the links between health and place, and does not recognize that therapeutic landscapes represent more than just physical or symbolic sites of healing. This is partly because therapeutic landscapes are primarily a "western" conceptualization that focuses on landscapes that are important in western cultures, for example spas (Wilson, 2003).

Until recently, therapeutic landscape research has been limited by failing to incorporate other ways of viewing the link between health and place. Wilson's (2003) groundbreaking work explored the everyday lives and geographies of First Nations peoples by exploring the importance of relationships to the land, as place, and its role in forming identity and health. Wilson discovered that the land, as place, is an integral part of First Nations people's identity and health. Interviews revealed that the land was not simply a physical space but rather, represented the interconnected physical, symbolic, spiritual and social aspects of First Nations cultures. Recent work by Donaldson (2007) conducted in collaboration with the community of Cape Dorset, Nunavut, further extends the concept of therapeutic landscapes to explore the way in which relationships to the land promote Inuit health in times of rapid economic globalization. This research illustrates that the complete interconnection of biological and non-biological aspects of 
the land is central to Inuit notions of health and healthy spaces. Having connections to the land is a vital part of Inuit identity and is associated with maintaining and improving health and wellbeing in everyday life (Donaldson, 2007). The work presented in this thesis aims to extend the work of Donaldson (2007) further to examine the importance of the land to the health and wellbeing of Inuit in the context of environmental change.

For Inuit, the land holds a deeper meaning that is closely linked to physical, emotional, spiritual and cultural health and wellbeing. Inuit have generations of experience hunting, fishing, gathering and living in close relationship with the land. To northern indigenous peoples, the term "land" has meaning beyond the physical landscape (Cobb et al., 2005 in: Berkes et al., 2005). Instead, the land holds a deeper, allencompassing meaning relating to the living environment, including humans. The land is a comprehensive concept of the environment that refers to plants, animals, and humans as well as the physical environment.

The environment has always been a source of livelihood and basis of culture for northern indigenous peoples (Cobb et al, 2005 in: Berkes et al., 2005). In the modern world, it continues to be vitally important in the mixed economy of northern communities in sustaining social relationships and distinctive cultural characteristics of a group. The environment helps maintain social identity and provides a source of social values, such as sharing. Traditional knowledge, ethics and values, and cultural identity are transferred to succeeding generations through annual, cyclical repetition of activities on the land, from berry picking to seal hunting (Freeman, 1993). Any loss of resources, or the health of the environment, has the potential to damage indigenous cultures through the loss of social 
relations of production, socialization of children, land stewardship ethics, and traditional knowledge.

The examination of the relationship between health and place (the land) in the context of environmental change remains an under-developed and poorly understood area of research. The Arctic environment, upon which Inuit depend, is undergoing significant environmental change. Inevitably, as the characteristics of the land change so too will the relationship of Inuit with the land and its resources. The implications for Inuit physical, emotional, spiritual and cultural health and wellbeing are significant, particularly in terms of safety when travelling and hunting on the land, and food security (Furgal, 2002 in Krupnik and Jolly, 2002). In order to gain a deeper understanding of the relationship between health and place (the land), the following section will discuss the role and significance of traditional foods in the maintenance of Inuit health and wellbeing.

\subsection{Importance of Traditional Foods to the Health and Wellbeing of Inuit}

This section presents a general discussion of the nutritional, socio-cultural and economic importance of traditional foods, followed by a discussion of the significance of seal, specifically, to the health and wellbeing of Inuit.

Inuit communities are widely recognized as having mixed, subsistence-based economies in which harvesting country food for primarily domestic consumption plays a significant role in their food security and culture (Usher et al., 2003). For millennia, Canada's Inuit people have been self-sufficient through subsistence-based activities, in the harsh Arctic climate without causing degradation to their environment (Usher et al., 2003). Although environmental change is nothing new, the magnitude and rate of change 
being observed in the Canadian Arctic due to climate change is unprecedented, and presents northern communities with a unique challenge. The advent of climate and environmental change has the potential to put the food supply and subsistence activities of northern communities at risk (Berkes et al., 2005), thereby putting Inuit health at risk.

Inuit people in the Arctic live in a harsh climate, with wildlife and other natural resources forming the basis of Inuit society, culture and economy (Berkes et al., 2005: 49). Inuit peoples in Nunavut have developed knowledge about plants and animals, their habitat preferences, local distribution, life histories, and their seasonal behaviour, with an interest in ensuring the long-term availability of the natural resources of their own localities. The transmission of this knowledge from one generation to the next, along with a philosophy of sharing has shaped customs that have promoted sustainability among Inuit. Much of this knowledge is used to obtain food, medicine, and other necessities.

The land is integral to Inuit health, because it is the land that provides Inuit with many sources of traditional foods. Traditional foods, also known as country foods, can be defined as the consisting of specific compositions of local products gathered and prepared in certain ways that are thereby meant to fulfill the nutritional and cultural needs of the population (Kuhnlein and Chan, 2000). Traditional foods include all of the food species that are available to a particular culture from local natural resources and the accepted patterns for their use within that culture (Kuhnlein et al., 2000). The term "traditional foods" also embraces an understanding of the socio-cultural meanings given to these foods, their acquisition, and their processing; the chemical composition of these foods; the way each food is used by age and gender groups within a selected culture; and the nutrition and health consequences of all these factors for those who consume these foods. 
Inuit traditional foods include marine and land mammals, fish, plants, berries, and waterfowl/seabirds harvested from local stocks.

Traditional foods play a vital role in food security, as well as the nutritional, social, economic, and spiritual wellbeing of Inuit communities in Nunavut (Thompson, 2005 in: Berkes et al., 2005). Northern indigenous people are well aware of the many benefits of traditional food systems, and as such these form an integral part of their holistic concept of health and well-being. Certain benefits are repeatedly emphasized in surveys regarding attitudes toward traditional foods: wellbeing, health, leisure, closeness to nature, spirituality, sharing, community spirit, pride and self-respect, economy and the education of children (AMAP, 2003: 75).

Traditional foods are essential to maintaining physical health and well-being according to several studies with Inuit communities. Data for the five Inuit areas $(n=$ 1,721 individual interviews) show that more than $80 \%$ of respondents agreed that harvesting and using traditional/country food by the family gives a wide range of cultural, nutritional and economic benefits (Thompson, 2005 in: Berkes et al, 2005). The nutritional benefits of traditional/country food and its contribution to the total diet are substantial, even though only $6-40 \%$ of total dietary energy may be from this food source (CACAR, 2003). New analytical results for nutrients in traditional/country foods have shown some remarkable nutrient properties. Many traditional/country foods contain excellent sources of vitamin C, omega fatty acids, vitamins A, D and E, as well as iron, zinc, selenium, copper, magnesium and manganese (CACAR, 2003).

Despite the awareness of the benefits of traditional food, during the last 50 years the energy content of the diet of indigenous peoples in most Arctic communities has 
increasingly been met by imported store-bought foods (AMAP, 2003: 75). For Baffin Island Inuit, market food now accounts for approximately $62 \%$ of their diet (AMAP, 2003). Research findings are consistent across the Canadian Arctic and confirm that decreasing traditional/country food in the diet is likely to have negative health consequences, in part through the corresponding increase in total fat, saturated fat and sucrose above recommended levels (CACAR, 2003). Reduced country food consumption in northern Aboriginal populations, coupled with decreasing physical activity, is associated with obesity, dental caries, anaemia, lowered resistance to infection, diabetes, and cardiovascular disease (Szarthmary et al., 1987; Thouez et al., 1989; CACAR, 2003).

In addition to their importance as a source of nutrition, traditional foods serve as a focus for cultural and social activities and help to maintain the social bonds within societies through traditional sharing of hunt/harvest and feasting together (AMAP, 2003: 75). Harvesting country foods tends to be inseparable from the social system (Usher et al., 2003). Economic relationships between households in a community are guided by kinship principles. Successful households do not accumulate wealth for their own private use; they share their produce with other households, distributing their excess production widely through the kinship system (Usher et al., 2003).

Hunting, fishing, trapping and gathering in order to obtain country food are an economic necessity for most Inuit communities in Nunavut. In most northern communities, fresh, nutritious store-bought food is expensive and rare and must be imported from great distances (Thompson, 2005 in: Berkes et al., 2005). Hunting, fishing and gathering in and around the community represents an economical means by which local people can obtain healthy food without significant financial burden. 
The following section will discuss in detail the nutritional, emotional and cultural significance of seal, in particular, to the maintenance of Inuit health and wellbeing.

\subsection{The Importance of Seal to Inuit Health and Wellbeing}

As detailed in the previous section, traditional foods are the product of a social system and spiritual relations connected with being on the land and hunting, representing far more than a meal, but rather a healthy culture (Usher et al., 1995). Inuit often speak of the necessity of eating country foods in terms of their physical, mental and cultural wellbeing. Harvesting seal mammals is perceived as an important traditional activity that connects modern day Inuit to their ancestral roots:

Sea mammals are considered to be the best food to feed the [Inuit] body... without these types of foods, we Inuit would have been gone a long time ago. Therefore, in order to live a full and happy life and to keep the generations going, we, the Inuit, need the food that has brought us to where we are today. (Freeman et al., 1993: 48)

Seal, in particular, is an important component of the Inuit concept of physical, emotional, spiritual, and cultural health and wellbeing. Seal in Inuit culture has many uses. From a nutritional standpoint, seal is considered "real food" imbued with the power to maintain health through nourishment of the body and soul (Borre, 1994). In terms of physical benefits, seal is widely recognized as being capable of generating warmth and strength in the body in a way that imported store-bought foods cannot. Foods that generate bodily warmth, such as seal, are essential dietary components for Inuit, who participate in various outdoor activities, such as hunting and fishing, in the harsh Arctic climate.

Seal is also praised for its medicinal properties, in the treatment and prevention of illness (Borre, 1994). Seal products, including blubber or oil, blood, broth and liver, are 
recommended to treat as well as to prevent illness from occurring precisely because of the ability of seal to provide warmth to the body. In the Inuit concept of health, in order for the body to be healthy it must be warm. A body that is not warm could develop an illness. If the body is not well, then soon the soul could become ill. Thus, in addition to treating ailments of the body, seal is also used to prevent weakness, depression and malaise, diseases of the soul. Seal has been used in the treatment of cuts, ear infections, headaches, nausea and weakness, hypothermia, lice, frostbite, and anaemia (Borre, 1994). The Inuit concept of health involving seal consumption is well-summarized in the following quote:

The Inuit concept of health is suggested by their use of seal to treat illness and prevent sickness. [...] Inuit health is maintained primarily through the consumption of seal and other country foods which keep the body warm. Body warmth allows one to achieve strength and endurance and maintains good mental health. When one has a healthy body and soul, he or she can then contribute to the production and distribution of country foods to help other maintain the wellbeing. In this way the health of individuals is directly tied to the maintenance of hunting relationships with the animals and with social relationships within the community. (Kirsten Borre, 1994: 12)

In addition to the medicinal and nutritional benefits of seal, dense and waterproof sealskin can be used for making traditional clothes, another effective way of keeping warm when on the land. Long before electricity, the fat of the seal was used to light the qulliq or oil lamp. Seal harvesting is also deeply linked to Inuit cultural identity and values:

The seal [...] provides us with more than just food and clothes. It provides us with our identity. It is through sharing and having a seal communion that we regain our strength, physically and mentally. (Peter et al., 2002: 167)

Inuit possess a deeply spiritual mythology surrounding the seal which is illustrative of Inuit morals and values. Traditional spirituality for Inuit was based on 
shamanism and survival on the land. Peter et al., (2002) recounts how Inuit ancestors believed that a seal would make itself available to a hunter, so that the hunter could harvest it. However, from the time the seal gave itself, the hunter had an obligation to share the seal with the people of his camp. If the hunter failed to honour this sacred obligation, the seal would not give itself to the hunter again when the seal's spirit would reincarnate. Sharing seal was part of the traditional way of life and ensured that more seals would be caught. The sacred obligation of sharing seal with the community remains an integral part of Inuit values, particularly during times of crisis when country food is scarce.

Given the nutritional, socio-economic, spiritual and cultural benefits of seal to Inuit, it follows that environmental changes which limit Inuit access to healthy seal populations, have the potential to place the health and wellbeing of Inuit at risk (Donaldson, 2007).

In the first portion of this chapter I have introduced the concept of therapeutic landscapes as a framework for studying the relationship between health and place (the land) in the context of environmental change for Inuit in the Canadian Arctic. I have also discussed the importance of the land and traditional foods, specifically of seal, to the physical, emotional and cultural health and wellbeing of Inuit. The focus of the chapter will now shift on a discussion of traditional ecological knowledge and Inuit Qaujimajatuqanjit and its usefulness in communicating recent observations of environmental change, and its impacts on health and wellbeing. 


\subsection{Defining Traditional Ecological Knowledge}

The following section provides a detailed discussion of the definition and characteristics of traditional ecological knowledge (TEK).

Traditional knowledge as a "way of life" has been part of indigenous culture for millennia. Indigenous people have used knowledge of their local environment to sustain themselves and to maintain their cultural identity. The literature uses various terms interchangeably to designate the concept of this type of knowledge, such as folk ecology, ethno-ecology, traditional environmental or ecological knowledge, indigenous knowledge, customary law, and knowledge of the land (Johnson, 1992).

Traditional knowledge or traditional ecological knowledge (TEK) is a body of knowledge built up by a group of people through generations of living in close contact with nature. TEK represents a collective understanding attained over long periods of time, in particular places, of the relationships between a community and the Earth (Doubleday, 1993). TEK may encompass spiritual, cultural and social aspects as well as substantive and procedural ecological knowledge. TEK may also include customary rules and laws, rooted in the values and norms of the community to which it belongs (Doubleday, 1993).

The terms indigenous knowledge and traditional knowledge are used in the broader sense to mean the knowledge specific to an area or culture, and TEK when the knowledge is of ecological nature; not all traditional knowledge is ecological (Berkes et al., 2005: 76). TEK is nonetheless, a problematic descriptor of that knowledge. Scholars note that the term "traditional" is rather ambiguous as it usually refers to cultural continuity transmitted in the form of social attitudes, beliefs, principles and conventions 
of behaviour and practice derived from historical experience (Berkes, 1993). By using the term "traditional" one risks implying a static or archaic form of knowledge that is inherently non-adaptive, whereas the acute observations and sophisticated knowledge that some aboriginal people have of their environment are both evolving and current, making it increasingly difficult to define just how change would affect the labelling of a practice as "traditional" (Usher, 2000; Berkes, 1993). It is for this reason that many scholars prefer the use of "indigenous" rather than "traditional" (Berkes, 1993; Usher, 2000; Wenzel, 2004). Having said that, the term "TEK" has passed into common usage, and is generally preferred by environmental researchers because it is more specific (Usher, 2000).

Any reasonably aware and competent person who regularly engages in smallscale activity in a natural environment year after year - whether it be farming, husbandry, or fishing-is likely to accumulate a wealth of observations that enable him or her to make certain generalizations, comparisons, and conclusions about natural phenomena (Usher, 2000). However, several factors enhance this knowledge among indigenous people. Their harvesting activities often occur over very large areas and over long periods of the year. Thus, the geographical and temporal scope of their environmental knowledge is generally much greater than that of a farmer or coastal fisherman, whose scope of operation is bounded by legal or customary property rights or by highly restricted harvesting periods (Usher, 2000). The diversity of activities, of animals and plants harvested, and of types of landscapes or coastal areas used is generally greater, and consequently the breadth of indigenous environmental knowledge and the scope of drawing connections among phenomena are greater. The fact that human activity on the 
land typically occurs within a framework of communal rather than private property relations, as well as mutual aid, facilitates continuity and sharing of experience. Long continuity of practice and of the geographic extent of land use greatly increases the likelihood that information will be transmitted and accumulated over generations (Usher, 2000). While TEK is not unique to indigenous culture or ethnicity, it is far more likely to be prevalent among indigenous people who continue to participate in a mixed, subsistence-based economy because of the property relations and continuity of practice that typify their communities (Usher, 2000).

There is no one widely accepted definition for TEK in the literature. If we sift through the various meanings and elements as emphasized in the major works on the subject we may arrive at this working definition:

TEK is a cumulative body of knowledge and beliefs, handed down through generations by cultural transmission, about the relationship of living things with one another and with their environment. Further, TEK is an attribute of societies with historical continuity in resource use and practices; by and large, these are non-industrial or less technologically advanced societies, many of them indigenous or tribal. (Berkes, 1993: 6)

However, indigenous people are more likely to frame their knowledge in terms of their experience. For example: practical common sense; teachings and experience passed through generations; knowing the country; rooted in spiritual health; a way of life; an authority system of rules for resource use; obligation to share; wisdom in using knowledge; using heart and head together (Berkes et al., 2005: 76).

TEK includes a system of classification, a set of empirical observations about the local environment and a system of self-management that governs resource use (Berkes, 1993). The quantity and quality of TEK varies among community members, depending on age, gender, social status, intellectual capability, and profession. For example, a 
subsistence hunter may have different TEK as compared to a local healer whose knowledge may be more centered on plants. With its roots in the past, TEK is both cumulative and dynamic, building on the experience of earlier generations and adapting to the new technological and socio-economic changes of the present (Berkes, 1993).

There are several aspects to the study of TEK such as: the categories used by the indigenous group for classifying various components of the environment; the empirical data on the environment (i.e. plant and animal behaviour, relationships between species, the interpretation of natural phenomena); the use of the environment (i.e. food, medicine, religion, technology, commerce); the management system employed to gauge the state of resources; and world view (or cosmology; the conception of the universe and of the place of human beings within it, in relation to all living things) (Mailhot, 1993).

Researchers have made various attempts to categorize TEK and identify which aspects may be useful to scientific investigations. For instance, Usher (2000) outlines a TEK schema which distinguishes different types of TEK in four categories:

- Category 1: Factual/rational knowledge about the environment. This includes statements of fact about such matters as weather, ice coastal waters, currents, animal behaviour, travelling conditions, etc, which are typically based on (a) empirical observations by individuals of specific events; (b) generalized observations based on numerous experiences over a long time period; (c) generalized observations based on personal experience reinforced by the accounts of others both living and dead (i.e. shared experience and oral history, respectively).

- Category 2: Factual knowledge about past and current use of the environment, or other statements about social or historical matters that bear on the traditional use of the environment and hence the rights and interests of the local aboriginal population in the region. Statements of fact are based on a range of knowledge from personal to oral history.

- Category 3: Culturally based values statements about how things should be, and what is fitting and proper to do, including moral or ethical statements about how 
to behave with respect to animals and the environment, and about human health and well-being in a holistic sense.

- Category 4: Underlying the first three categories is a culturally based cosmology — the foundation of the knowledge system - by which information derived from observations, experience and instruction is organized to provide explanations and guidance. It is the framework with which people construct knowledge from facts.

In the past, "outsiders" (i.e. social, physical, and agricultural scientists, biologists, colonial powers) disregarded or maligned TEK depicting it as simple, static, not knowledge, or folklore (Grenier, 1998). However, for the past two decades this knowledge system has been gaining recognition by the Western scientific community as a valuable source of ecological and cultural information. TEK is increasingly praised as an "alternative collective wisdom relevant to a variety of matters at a time when existing norms, values and laws are increasingly called into question" (Grenier, 1998: 6). TEK has been prominent in the discourse surrounding land and resource management and decision-making. Because of its acknowledged connection with environmental sustainability and the empowerment of marginalised peoples, it has been variously analysed, systemised and incorporated into environmental assessment, land claim and treaty entitlement processes and wildlife management and land-use regulation (Ellis, 2005). The land claim agreements bring TEK into the forefront for environmental management in the North. TEK has become a key mechanism for implementing participatory management in a number of areas of resource management, including monitoring (Berkes et al., 2001). 


\subsubsection{Distinguishing Inuit Qaujimajatuqanjit from TEK}

The previous section provided a definition and background information about traditional ecological knowledge (TEK). TEK is a term that is commonly used by researchers working with indigenous groups and local knowledge. However, the term TEK falls short of grasping the complex social, cultural and spiritual dimensions of Inuit knowledge. This is why the preferred term when working with Inuit knowledge is Inuit Qaujimajatuqanjit (or IQ), which is a far more all-encompassing concept.

Inuit Qaujimajatuqanjit is defined as "an accumulated and evolving body of knowledge that comprises the inter-generational survival skills, beliefs, practices wisdom and experiences of Inuit as people who demonstrate an acute awareness of dynamic interactions between themselves, lands, and resources" (Bourgeois, 2006). It is through this dynamic and adaptive learning process that Inuit have been able to respond and adapt to both past and present environmental changes. Meant to be the central philosophical tenet of the Government of Nunavut (GN), Inuit Qaujimajatuqanjit encompasses all aspects of traditional Inuit culture including values, world view, language, social organization, knowledge, life skills, perceptions and expectations (Wenzel, 2004). Inuit Qaujimajatuqanjit is a "living technology" through which Inuit thoughts and actions, tasks and resources, family and society, are organized (Wenzel, 2004: 242).

Inuit Qaujimajatuqanjit was conceived for several reasons. The first related to how narrowly non-Inuit social and natural scientists seemingly understood Inuit traditional knowledge to be-essentially as being limited to specific aspects of animal species and the environment. The point to be made was the Inuit traditional knowledge 
encompassed far more than what is generally called TEK. There was a desire to develop an Inuktitut term that freed the overall body of what constituted Inuit Qaujimajatuqanjit from TEK's narrowness. Traditional ecological knowledge (TEK) is not by any means the whole of IQ, although such knowledge is certainly part of IQ. The fact that IQ is often equated with TEK, however, diminishes the depth of its socio-cultural content and importance (Wenzel, 2004). Indeed, TEK, when it is limited to basic observations of natural phenomena, offers little to our understanding of Inuit cultural ecology (Wenzel, 2004). The following section discusses the contributions of TEK and IQ to the study of environmental change in the Canadian Arctic.

\subsection{Using Traditional Ecological Knowledge and Inuit Qaujimajatuqanjit to Monitor Environmental Change}

Environmental change, detected through local observations and traditional knowledge, has been shown to enrich the understanding of Arctic climate change (Berkes et al., 2005: 77). Local observations and place-based research are important for understanding ecosystems because ecosystems are complex systems, and information is needed at multiple scales. While scientific models generally dominate the ecosystembased discussions of environmental change, researchers are beginning to question whether purely scientific models, alone, can provide the whole answer. Cobb et al (2005) argue that scientific models, without local observations of change, are limited in their explanatory power due to intra- and inter-regional variations. In addition, models do not directly address the major human and ecological impact of environmental change, which is not so much about mean change, but rather about the local impact of changes on such 
factors such as food, nutrition and culture (Berkes et al., 2005: 77). The shortcomings of global and regional models can be seen in the case of climate change research in which local observations and understandings are needed to supplement models (Krupnik and Jolly, 2002). Traditional knowledge can contribute to a fuller understanding of local environmental processes "at finer and more detailed geographical scales than conventional scientific knowledge can offer...because it deals with outcomes and predictions: what people think and why" (Usher, 2000: 187).

Scientific understanding of Arctic environmental and climate change is based on records that are often short-term and/or fragmentary. Weather records and sea ice data are available for some places, but rarely extend back before the twentieth century. Satellite monitoring of snow, ice or other parameters covers most or all of the Arctic, but only for recent decades, if not years. Process studies have been carried out in several locations around the Arctic, giving insight into the dynamics of ecological processes but leave open the question of how to extrapolate those findings across the vast areas where no such studies have taken place. Paleo-environmental and archaeological records reveal a great deal about certain indicators of climatic, environmental and social conditions but require careful and cautious interpretation. Add to the mix the fact that the Arctic environment is highly variable, compounding the difficulty of identifying trends and causal relationships.

Arctic residents have long known about and had to cope with this variability. The intimate knowledge of Arctic peoples and their surroundings is well known. However, the applicability of this knowledge to scientific studies of environmental change and ecological systems is still in the beginning stages. The Earth is Faster Now (Krupnik and 
Jolly, 2002) addresses indigenous observations of Arctic environmental change and the implications of such change for Arctic peoples. The nine papers collected in the volume focus primarily on documenting and understanding the nature of changes that are being observed by northern indigenous residents in their environment. The compilation of studies is at the forefront of community-based, place-based research and provides detailed examples of how science and traditional knowledge can be complimentary sources of knowledge about environmental change.

Some of the first attempts to understand environmental change using traditional knowledge came from the Hudson Bay Bioregion Project (McDonald et al., 1997), the Northern Rivers Basin Study (Bill et al., 1996) and the Mackenzie Basin Impact Study (Cohen et al., 1997). There are now a growing number of studies that demonstrate the value and utility of traditional ecological knowledge in climate change research in the Arctic (Ferguson et al., 1997; Lyver et al., 2005) and more specifically the local knowledge of Inuit. Fox's research (1998; 2000; in Krupnik and Jolly, 2002: 13) illustrates the detailed knowledge of Inuit to patterns, variability and changes in the environment. The Tuktu and Nogak Project documented Inuit Qaujimajatuqanjit (IQ) about calving grounds and calving areas in the Bathurst Inlet region of Nunavut (Thorpe 1997; 2000). The Arctic Borderlands Ecological Knowledge Co-op has used IQ to monitor the migratory Porcupine caribou herd (Kofinas et al., in Krupnik and Jolly, 2002: 55). The Inuit Observations on Climate Change (IOCC) project documented Inuvialuit observations of climate change involving the western Arctic community of Sachs Harbour, on Banks Island, Nunavut. IQ has contributed to a deeper understanding of the effects of environmental change on sea ice condition, seasonality, weather patterns, the 
health wildlife and the health of local people. These studies are proof that IQ is a valuable source of information that can enhance the understanding of climate and environmental changes in the Arctic.

\subsection{Inuit Observations of Changes to Ringed Seal Health}

While the cases are few, there are an increasing number of Inuit observations documenting changes to ringed seal health and body condition, spanning the Arctic. Inuvialuit hunters from Sachs Harbour in the western Canadian Arctic have noticed that seals are sinking to a deeper water level at the floe edge, a phenomenon attributed to a lowered fat content (Riedlinger and Berkes, 2001). Inuvialuit from Sachs Harbour have also reported an increasing occurrence of "skinny" seal pups at spring break-up (Krupnik and Jolly, 2002: 108).

Similar reports have been documented in the eastern Arctic. The following quote is by an Inuit hunter from Nain, Labrador: "We see more sick seals now too. Some that you kill are just skin and bones and hair" (Krupnik and Jolly, 2002: 282). Elders from Nain have reported seal habitat has changed. There is little snow on the ice. This has made it hard for seals, as they have nowhere to build dens and breathing holes. Habitat changes, such as the lack of snow on the ice, have also been physically hard on pups which have been reported as showing more scratches on their stomachs (Krupnik and Jolly, 2002). Nunavimmiut (Nunavik Inuit) from Kuujjuaq have reported changes in seal distribution: "I know today that seals, it might be because of early spring break-up or that they are out on the ice floes, but the seals are nowhere" [sic] (Krupnik and Jolly, 2002: 284). 
Local evidence is accumulating that suggests ringed seals are being negatively impacted by climate and environmental change in the Canadian Arctic. Understanding how environmental change may be affecting the number, distribution and availability of ringed seals is an important, yet poorly understood aspect of research. Ringed seals are nutritionally, socio-economical, spiritually and culturally significant to Inuit. Changes to the health and availability of ringed seals may place the health and wellbeing of coastal Inuit communities at risk, and therefore, warrants further study. The following section will discuss the potential impacts of environmental change to the health of seals.

\subsection{Sea Ice as an Important Substrate for Ringed Seals}

The previous sections of this chapter have established the importance of the land, as place, and of seal to the health and wellbeing of Inuit. It is now important to establish how environmental change may impact the health of ringed seals themselves, as this has the potential to directly impact the health and wellbeing of Inuit.

Climate and environmental change in the Arctic region is expected to be more significant than in any region on Earth (IPCC, 2007). Warming in the Arctic has lead to overall decreases in the distribution and abundance of both annual and multiyear sea ice, and is expected to continue at an increased rate of change (Serreze et al., 2000; Comiso, 2003). Related to the decline in sea-ice extent are a decrease in the length of the sea-ice season, and an increase in the length of the Arctic summer melting season (Parkinson, 2000; IPCC, 2001). Scientists predict that a sustained decline in sea ice at the present rate would mean the disappearance of multiyear ice cover during this century, and drastic changes in the Arctic environment (Comiso, 2002). 
The implications of declining sea ice are significant to the health of Arctic marine mammals, most of which are specifically adapted to the sea ice environment. Sea ice is a vital substrate for pagophilic, or "ice-loving", mammals and epontic (under-ice) algal communities. Significant reductions or the disappearance of sea ice from some areas will fundamentally alter the Arctic marine ecosystem as we know it today (Derocher et al., 2004). As sea ice shrinks, so too will the number of critical habitats available for Arctic marine mammals to occupy (Anderson, 2001). Critical habitats are defined as "those identifiable areas, which are vital to the survival of a marine species at some phase in its life cycle" (Harwood, 2001: 631).

One species that risks being dramatically affected by changes in sea ice is the ringed seal (Phoca hispida). In a warmer Arctic, pinnipeds, like ringed seals, may be directly affected by changes in the availability of suitable ice-associated habitat (Tynan et al., 1997). Ice-associated seals are thought to be particularly vulnerable to changes in the extent and concentration of sea ice because they depend on pack-ice habitat for pupping, foraging, moulting and resting (DeMaster et al., 1995).

Several aspects of ringed seal health may be impacted by changes in sea ice. For instance, changes in sea ice may lead to changes in primary and secondary productioncritical sources of food that sustain ringed seals. It is well recognized that ice algae play an important role in sustaining the secondary production that supports marine mammals in the Arctic (Tynan et al., 1997). In spring, ice algae form a thin, dense layer (approximately $1 \mathrm{~cm}$ ) dominated by pinnate diatoms, on the underside of the ice at the ice-seawater interface (Cota et al., 1989). Studies have indicated that epontic algae 
sustain a large biomass of sub-ice invertebrates and fish (Stirling, 1997). Cryopelagic fishes such as Arctic cod (Boreogadus saida) are especially adapted to feed under the ice as suggested by the placement and orientation of the mouth. Arctic cod rely on the abundance of crustaceans associated with the ice under-surface and the adjacent water column (Lonne et al., 1989). The Arctic cod is a pivotal species in the Arctic food web as evidenced by its importance as a prey item to belugas, narwhals, harp seals (Phoca groenlandica), bearded seals, hooded seals (Cystophora cristata) and ringed seals. In Arctic regions, no other prey item compares with Arctic cod in abundance and energetic value (Finley et al., 1990). It is difficult to predict how Arctic cod may be redistributed in a warmer Arctic. However, since their life history is closely linked to sea ice, researchers speculate that regional changes in the extent of sea ice may lead to redistributions of Arctic cod and consequently to redistributions and altered migrational patterns of marine mammals, such as ringed seals, which rely on the ice edge community for foraging (Tynan et al., 1997). If seal were in fact suffering from lack of adequate food supply, the affects of this would be observable in the overall body condition of the animals. Body condition is a useful indicator, when monitoring the health of mammals. Body condition an indicator of health that is employed by indigenous people and researchers alike. The following section discusses the use of body condition as an indicator of seal health.

\subsection{Body Condition as a Measure of Environmental Stress}

One of the primary objectives of this research is to monitor the body condition of ringed seals using traditional knowledge. But why is the study of body condition significant and how is it indicative of health? Body condition is represented by any 
number of physiological indices representing an animal's energy reserves such as fat deposits, blood chemistry and growth rates (Evans et al., 2003). The study of body condition is important in monitoring the health of animal populations and may contribute to greater understanding of changes in the size of animal populations (Beck et al., 1993). The evaluation of body fats helps in the assessment of the status of animal populations and can reveal environmental adaptation. In marine mammals, the level of fat reserves, stored principally in the blubber, has been considered the best indication of body condition (Maclaren and Smith, 1985). Fat deposits in blubber serve as an energy store, as a source of buoyancy and streamlining and as insulation (Beck et al., 1993). Variation in deposited fat reserves in marine mammals is known to influence the onset of sexual maturity, ovulation rates, lactation, reproductive success, and survivorship during times of environmental stress (Evans et al., 2003; Beck et al., 1993; Beck et al., 1995). Harwood et al. (2000) reports that mature female ringed seals that had experienced ovulation had significantly better body condition than those that had not ovulated. Furthermore, percentage of body fat is an indicator commonly used by indigenous people to interpret and communicate about the health of seals and other wildlife (Parlee et al., 2005 in: Berkes et al., 2005). It is a characteristic that easily observed, particularly in Arctic sea mammals, which have substantial amounts of blubber, and provides great insight into the health status of wildlife. It is for all of these reasons that body condition was chosen as an indicator of health in this study.

The Arctic environment is undergoing significant change. Yet, the relationship between health and the land, as place, in the context of environmental change is poorly understood. Inuit across the Canadian Arctic are witnessing firsthand changes to the land 
and resources upon which they have depended for thousands of years. The land, as place, is an integral component of Inuit identity, health and wellbeing. The land provides Inuit with sources of country food, which are nutritionally, socio-economically, spiritually, and culturally significant. Seal, in particular, is an integral part of Inuit identity, spirituality and culture. However, environmental change has the potential to negatively impact the health of ringed seals, thereby placing the health and wellbeing of Inuit communities at risk. 


\section{Chapter 3}

\section{Research Approach and Methods}

The research process, then, is not a clear cut sequence of procedures following a neat pattern, but a messy interaction between the conceptual and empirical world, deduction and induction occurring at the same time.

-Bryman and Burgess, 1994: 2.

\subsection{Research Approach}

The qualitative methodological framework used in this study was based on community-based traditional knowledge research, which stems from the broader methodological approach, participatory action research. The following section describes these qualitative approaches in greater detail.

\subsubsection{Participatory Action Research}

Participatory action research (PAR) is a powerful strategy to advance both science and practice (Whyte, 1989). PAR is defined "as a form of action research in which professional social researchers operate as full collaborators with members of organizations in studying and transforming those organizations" (Greenwood et al., 1993: 177). PAR is a research approach that emphasizes co-learning, participation, and organizational transformation. In PAR, the organization or community under study participate actively with the professional researcher throughout the research process from initial design to the final presentation of results and discussion of their action implications (Whyte, 1991: 20). PAR enhances problem formulation, hypothesis 
formulation, data acquisition, data analysis, synthesis, and application. Greenwood et al.,

(1993) outline the key features of PAR into the following categories:

- Collaboration: PAR involves collaboration between members of the organization being studied and a professional social researcher. It takes places across the whole research process from problem formulation to the application and assessment of the results.

- Incorporation of Local Knowledge: PAR incorporates the knowledge and analysis of members of the organization or community under study in support of the research process.

- Eclecticism and Diversity: The PAR approach is purposely multidisciplinary and eclectic. It mobilizes theories methods, and information from whatever source the participants jointly believe relevant.

- Case Orientation: Building theory and method in PAR is an intrinsically caseoriented activity. It attempts to learn general lessons from specific cases, to operationalize concepts, to develop comparisons, and the like, through repeated case applications.

- Emergent Process: PAR is seen as an emergent, intensifying process that is able to gain increased depth and dimension throughout the entire research process.

- Linking Scientific Understanding to Social Action: Because the majority of the participants in the research process are from within the organizations under study, the research results reflect their understanding of their own system better than the work of external professional researchers alone could. These understanding are also conditioned by organization members' rights and obligations to act within their own system. Thus, pluralistic and self-managed participation in the research process is capable of producing both scientifically and socially meaningful research results.

PAR thus contrasts sharply with the conventional model of pure research, in which local people are treated as passive subjects, and researchers are treated as professional experts, thereby reinforcing an elitist model of research relationships (Whyte, 1991). 


\subsubsection{Community-based Traditional Knowledge Research}

As previously discussed in Chapter 2, traditional knowledge and its application to climate change-related monitoring programs is receiving increased recognition by the broader scientific community. Arctic environmental change, with its multitude of uncertainties, does not lend itself to analysis by conventional approaches.

As science-based understandings of Arctic environmental change, community assessments are evolving. Researchers who have worked within indigenous communities have tried various approaches to develop a practical model to build connections between western scientific knowledge and traditional knowledge (Zampora, 1996). Methods include the use of focus groups, workshops, working committees, and training community researchers in order to bring scientist and indigenous groups together to create idea and develop joint ventures (Zamparo, 1996). Still, very little research has been done to explore the value of traditional knowledge related to climate and climate change research (Riedlinger and Berkes, 2001). Furthermore, there are no established conceptual frameworks on how to bridge the gap between Inuit knowledge and western science. In this burgeoning field, the challenge of developing of appropriate methods and procedures is still being tackled (Riedlinger, Master's thesis, 2001).

However, researchers are seeking out new ways to approach community-based traditional knowledge research, in the hopes expanding the scope of conventional climate change research practices. The methodological approach used in this study was strongly influenced by the five convergent themes listed above suggested by Riedlinger and Berkes (2001). Table 3 shows five areas of potential convergence to link traditional 
knowledge with western science, specifically related to climate and climate-change research, suggested by Riedlinger and Berkes (2001). 
Table 3.1. Five convergence areas that can facilitate the use of traditional knowledge and western science, in the context of Arctic climate change *.

\begin{tabular}{|c|c|}
\hline Local-scale expertise & $\begin{array}{l}\text { The integrity of traditional knowledge at the local scale } \\
\text { has been promoted in discussions of traditional } \\
\text { knowledge in the north. Climate change will be first } \\
\text { noticeable through biophysical changes in sea ice, wild } \\
\text { life, permafrost, and weather. Theses changes will not } \\
\text { go unnoticed at the local scale in Inuit communities. }\end{array}$ \\
\hline Climate history & $\begin{array}{l}\text { Traditional knowledge can provide insight into past } \\
\text { climate variability, providing an essential baseline } \\
\text { against which to compare change. Climate history is } \\
\text { embedded in Inuit history of wildlife, travels, extreme } \\
\text { events, and harvesting records. }\end{array}$ \\
\hline Research hypotheses & $\begin{array}{l}\text { Traditional knowledge can contribute to the process of } \\
\text { formulating scientific hypotheses as another way of } \\
\text { knowing and understanding the environment. } \\
\text { Collaborations at the initial stage of research expands } \\
\text { the scope of inquiry and establishes a role for } \\
\text { communities in research planning. }\end{array}$ \\
\hline Community adaptation & $\begin{array}{l}\text { Traditional knowledge lends insight into adaptations to } \\
\text { changes, explaining them in the context of livelihoods } \\
\text { and community life. How are communities responding } \\
\text { to change? What are the social, economic, and cultural } \\
\text { limits to adaptation in northern communities? }\end{array}$ \\
\hline Community-based monitoring & $\begin{array}{l}\text { Traditional knowledge reflects a cumulative system of } \\
\text { environmental monitoring and observation. Monitoring } \\
\text { projects have the potential to bridge the gap between } \\
\text { science and traditional knowledge by providing a } \\
\text { collaborative process. }\end{array}$ \\
\hline
\end{tabular}

*The information given in Table 3 was taken from: Riedlinger D., Berkes F. Contributions of traditional knowledge to understanding climate change in the Canadian Arctic. 2001. Polar Record 37(203): 315-328. 


\section{(1) Local-scale expertise}

The ecological expertise found in Inuit communities can highlight parameters rarely measured by scientists and help make sense of scientific findings by placing them in a local context. Changes in climate are recorded and experienced by local people. Time and place-specific empirical observations can help explain larger-scale phenomena.

\section{(2) Climate history}

A second area of convergence for the use of TEK and scientific approaches together, concerns change over histories time. Climate history of the Arctic is key to understanding future (and present) climate change. Scientific understanding of the climate change in the Arctic is based on records that are often short and fragmentary (Krupnik and Jolly, 2002: xxiii). Therefore, traditional knowledge can provide another source of climate history providing important baseline data which to compare change.

\section{(3) Formulating research questions and hypotheses}

A third area of convergence for the use of traditional knowledge and scientific approaches together, is the process of formulating research questions and hypotheses. Even if it were known how to measure climate change in the Arctic, it is still crucial to know what to measure (Riedlinger and Berkes, 2001: 319).

\section{(4) Community adaptation}

A fourth area of convergence for traditional knowledge is its use in community adaptation. Understanding the human dimensions of climate change is an important 
aspect of climate change research, but is poorly understood. The key to understanding the impacts of climate change on northern communities is through the perspective of northern people. Awareness of climate change in the Arctic, as described and explained by Arctic communities, may provide the necessary impetus to policy-makers and governments to plan more effectively in addressing impacts of climate change (Riedlinger and Berkes, 2001).

(5) Community-based monitoring

A fifth area of convergence for traditional knowledge and science can be through the establishment of community-based monitoring programs. Monitoring can be collaborative, bridging the gap between scientists and communities by combining synchronic and diachronic information. Such projects enable local input into the environmental variables to be monitored.

Community-based programs have already been in place for the monitoring of sea ice (Macdonald et al., 1997, Huntington, 2000; Riedlinger et al., 2001; Krupnik and Jolly, 2002; Nichols et al., 2004), and Arctic caribou body condition (Ferguson et al., 1997;

Thorpe, 1997; Krupnik and Jolly, 2002; Lyver et al., 2005). The success of these studies illustrates the value and potential of a community-based approach to research.

\subsection{Methods}

\subsubsection{Study Area}

This research was conducted in the community of Cape Dorset, Nunavut $\left(64^{\circ} 14^{\prime} \mathrm{N}, 76^{\circ} 32^{\prime} \mathrm{W}\right)$. Cape Dorset, whose traditional name is Kingait meaning 
mountains, is situated between two valleys of the Jinait Range of hills and is considered to be part of the Foxe Peninsula, of southwest Baffin Island (INAC, 2006). Known as the Inuit Art Capital of Canada, Cape Dorset's major economic activities include hunting, carving, tourism, art, and printmaking. Cape Dorset with its predominantly Inuit population (93.4\% Inuit; $6.6 \%$ non-Inuit; Aboriginal Peoples Survey, 2001) and extensive traditional knowledge base represents an ideal location for this interdisciplinary study.

\subsection{Data Collection}

\subsubsection{Interviews}

Inuit Qaujimajatuqanjit (IQ) was documented by method of semi-directed (or open-ended) interviews (Huntington, 1998). One of the benefits of using semi-directed interviews as a key method of data collection is that they allow for a fair amount of flexibility and adaptability for the researcher and the informant (Usher, 2000). The informant can express his/her point of view, relate to personal experiences, narrate stories or anecdotes; all elements that might contain relevant information for the researcher (Poirier et al., 2000). While the researcher proposes the leading thread, the interviews take more the form of a dialogue than a formal question and answer session (Poirier et al., 2000). An interview guide was prepared comprised of broad themes and questions (Figure 1). The interviews were however not limited to the questions on the interview guide. Both I and the participants had the freedom to pursue and develop any topics of interests that were raised in conversation. 
An essential issue in IQ research concerns the means by which local knowledge experts are identified (Davis et al., 2003). This goal must be a critical initial focus of IQ research design since not all persons within local settings are of similar stature in terms of the substance and character of their knowledge (Davis et al., 2003). Having considered this point, the participants were chosen strategically. Considering the nature of the study, and the need for rather specific information regarding sea ice and ringed seal body condition, the community members that were approached had extensive knowledge of hunting and preparing seal. In order to identify potential participants I relied upon the advice and expertise of local partners, Pootoogoo Elee and Silaqqi Alariaq, who were also the interpreters that I worked with during this study. Both were well-known throughout the community, and knew which members of the community actively hunted seal. Based on their knowledge, we were able to formulate a list of potential participants. Community members were then contacted by telephone, given background information about the study and invited to participate. If the community member wished to participate we then scheduled an interview at a time and place convenient for them.

A total of 17 in-depth interviews were conducted ( 7 women, 10 men). Interviews were recorded by hand, and typically ranged from 30 minutes to 1.5 hours in length. The interviews were conducted in English and Inuktitut, with the aid of two interpreters, Pootoogoo Elee and Silaqqi Alariaq. The majority of the interviews were conducted in the community Visitors Centre, located at the centre of town. Exceptions were made, however, for participants that preferred to be interviewed in their homes. Certainly a critical issue in traditional knowledge research is the means by which local knowledge “experts" are identified (Davis et al., 2003). This goal must be a critical initial focus of 
traditional knowledge research design since not all persons within a local setting are of similar stature in terms of the substance and character of their knowledge (Davis et al., 2003). Consequently, the first step in conducting traditional knowledge research must involve some means to identify the most knowledgeable persons. A related issue concerns the specification of the knowledge domain or domains under inquiry. Those deriving their livelihoods in primary or natural resource settings will have a wide variety of experiences and observations. Choices have to be made regarding the selection of the resources and livelihood-related activities on which the study will focus. In the case of this study, knowledge regarding changes in ringed seal health and sea ice conditions were considered the foci.

Having considered these points, the participants were chosen purposively (i.e. strategically). Considering the focus of the study and the need for specific information regarding changes in seal health and sea ice conditions, the community members were chosen who had extensive knowledge of these areas. Being a relative newcomer to the community, I relied on the recommendations of the two interpreters whom I worked with to help identify potential participants. In order to ensure that a broad range of perspectives were represented in the interviews, we were sure to include both male and female participants of varying ages. However, the ages and sexes of the participants were not disclosed due to the small sample size of interviews. Doing so may have put the anonymity of the participants at risk. The seventeen interviews reported in the thesis represent a wide range of perspectives which reflect the broad and varied experience of Cape Dorset residents themselves. Through the observations and experiences of the 
participants there emerges clear consensus around the fact that environmental change is occurring in the Cape Dorset area, the effects of which are impacting the lifestyles and livelihoods of residents.

\subsection{Analysis}

Completed interviews were transcribed for qualitative content analysis. In qualitative content analysis, as described by Tesch (1990), data is not reduced to simple frequencies of their occurrence. Instead, this type of analysis endeavours to take into account the context, content, and significance of all responses given during interviews. In this study, the data was thoroughly and repeatedly reviewed to develop groups or categories of related information. The format of groupings presented here is recognized as one of several potential ways of relating the information to the reader. This method of analysis was chosen as a powerful way to present traditional knowledge to the reader in its complete, rich form as experienced by the participants. 


\section{Chapter 4}

\section{Results}

\subsection{Inuit Observations of Environmental Change in Cape Dorset, Nunavut}

The residents of Cape Dorset, Nunavut have generations of experience hunting, travelling and living in close relationship with the land. In recent years, they have noticed numerous changes in their environment, many of which they have never experienced before now. Changes that are being observed are having an impact on the health, wellbeing, and livelihoods of local people. The local observations presented below are organized into three sections. The first section documents local observations of changes to sea ice in the Cape Dorset area. The second section documents observed changes in weather patterns. The third and final section in this chapter focuses on traditional knowledge regarding ringed seal health, and the importance of seal to Inuit physical, emotional and cultural wellbeing.

\subsection{Changes in Sea Ice Conditions}

The residents of Cape Dorset that were interviewed for this study report changes to the structure and stability of sea ice, in and around, the Cape Dorset area. All participants report significant changes to the texture, thickness and stability of sea ice. Sea ice is not as hard or as thick as it used to be, and is increasingly viewed as unsafe by residents at particular times of the year: 
The ice is not as thick as it used to be and not as hard as it used to be. A lot of Elders have been going on the radio saying that the ice is not thick enough and to be careful. We hear that a lot more often and we are hearing that from our elders! (Inuit hunter, Cape Dorset, 2006)

The ice isn't like it used to be. The ice is not as thick as it was. The frozen ice is always breaking up. When it used to freeze it would stay frozen. It used to be that way. The thickness of the ice is less because it's always breaking early. (Inuit Elder, Cape Dorset, 2006)

The thickness of the ice is 3 to 4 feet at the most. I used to remember it being 5 to 6 feet deep or more. (Inuit Elder, Cape Dorset, 2006)

Participants report significant changes to the timing of both break-up, and freezeup of sea ice. Traditionally, the ice would begin to melt slowly during springtime, from the period of late June to early July. Conversely, the ice would begin to freeze in late fall, during the period of late November to early December. The climatic conditions of recent years have brought changes to that observed pattern. Residents have observed that in the spring, the ice has been melting up to two months earlier, and at a faster rate. Similarly, in the fall, the ice has been taking longer to freeze, resulting in a reported delay of one to two months. The combined effect of an early break-up and late freeze-up has resulted in prolonging the ice-free period. Participants have also reported that the floe edge is much closer to shore than in years past: 
It has changed within the last 40 to 50 years. Freeze-up is not as fast as it used to be. It used to freeze up in the month of November. It would freeze up right away. That doesn't happen any longer. In the last couple of years the ice is forming in the month of December around Christmas. The ice doesn't freeze in November anymore. When the ice does form in November it just breaks off, it only stays in December. In April the ice breaks up instead in the month of June. It's about 3 months off for freeze-up and break-up than it was before. In the last 50 years the floe edge is a lot closer to shore. It used to be 2 miles further. (Inuit Elder, Cape Dorset, 2006)

The ice is starting to freeze later. By November/December, the ice starts to finally go out in the bay. When I was a teenager the ice was freeze in October. Now at that time I can hardly see any ice. Break-up was pretty early, around May. There was no ice in June and I couldn't believe it. It used to melt by July. It's starting to melt faster every spring and freeze later. (Inuit hunter, Cape Dorset, 2006)

\subsection{Changes in Weather Patterns}

\subsubsection{Temperature}

Residents of Cape Dorset have observed several changes in weather in recent years. For instance, participants report warmer temperatures throughout the year. In particular, participants report harsher summers with more hot spells, and warmer, shorter winters: 
Years ago it used to nice and warm, now it's warm but not the same kind of warm. Now you get more burns and snow blindness. It is harsher this summer. (Inuit Elder, Cape Dorset, 2006)

In the month of March it felt like May, because of the warm spells which we usually get in May. This past winter wasn't as cold as it used to be, not like the winters we had years ago. (Inuit hunter, Cape Dorset, 2006)

While the majority of participants believed the warmer temperatures to be a recent change, one participant believed that the weather he experienced as a child was returning:

The weather I had when I was a child is coming back. It used to be hot back then. We had to put extra canvas on our tent to cool it down, and lift up the tent to let out the heat. When I was young we didn't use the Coleman stove, we had to cook from outside the tent because it was so hot. The year 2006 seems to be the hottest year since I was a child. The old days are coming back. (Inuit Elder, Cape Dorset, 2006)

\subsubsection{Rainfall}

Over half of participants report an increase in rainfall, particularly during the winter months. However, it is interesting to note that several Elders report that while the rainfall has increased in recent years, there was far more rainfall when they where children: 
It has been raining more this year than last year. I have noticed more rain than usual. (Inuit hunter, Cape Dorset, 2006)

We are getting some rain, enough for the plants to grow, but not as much as we used to. Rain would come so much in the past that the berries would drown. (Inuit Elder, Cape Dorset, 2006)

\subsubsection{Wind patterns}

Participants report an increase in the strength and severity of winds during the winter and summer months. Wind patterns have become unpredictable, often coming from all directions at once. Stronger, more unpredictable winds have made it increasingly difficult for hunters to accurately predict the weather, because it changes so quickly, often without warning:

When I listen to the weather forecast, the wind is supposed to come from one direction and then it changes. So the weather forecasts aren't usually right these days. A hunter will predict the weather, saying the wind will come from one direction, and the wind will come from all directions in the same day! (Inuit Elder, Cape Dorset, 2006)

\subsubsection{Snow}

Residents report a decrease in snowfall during the winter months. The depth, quality and texture of snow have noticeably changed in recent years. Participants 
observed that stronger winds were partially responsible for changes in the quality and depth of snow in the area. As a result, residents have difficulty constructing traditional igloos, which are used as a temporary shelter when on the land:

The snow used to be as tall as your waist. Now it hasn't been more than 3 feet high. The snow used to be 3 to 5 feet high. (Inuit Elder, Cape Dorset, 2006)

The snow in the winter isn't as much. There are more wind spells. The snow should be much thicker if we weren't getting all the wind we get today. When I used to travel on the snow, I would get stuck more often, but not now. (Inuit hunter, Cape Dorset, 2006)

There is much less snow and less packed snow. Now if there is any snow it is powdered and just blows away. (Inuit Elder, Cape Dorset, 2006)

\subsection{Inuit Observations of Ringed Seal Health}

One of the primary focuses of this study was to document Inuit Qaujimajatuqanjit of ringed seal health, and the socio-cultural importance of seal hunting to culture in the community of Cape Dorset, Nunavut. The following section provides a detailed account of how Inuit hunters know a seal is healthy and safe to eat. 


\subsubsection{Characteristics of Healthy Ringed Seals}

Hunters in the community of Cape Dorset use an extensive set of criteria to determine whether or not a harvested seal is fit to eat. When asked to describe this criteria a common response was that "hunters know what they have to do", illustrating the depth, confidence, and reliability of this traditional knowledge. The criterion is made up of a series of external and internal cues, each of which provides valuable information regarding the overall condition of the harvested animal. The characteristics of a healthy versus unhealthy seal are summarized below:

-Hair: A healthy seal has thick, continuous fur, and strong hair that is not easily removed. An unhealthy seal may have bald spots on the fur, and hair that is easily removed. An unhealthy seal may also have oil in its fur.

-Eyes: Healthy seals have big, black eyes.

-Other external abnormalities: An unhealthy seals may have external abnormalities that tell hunters an animal is unfit to eat. External abnormalities include flippers that are stuck together, seal with deformed mouths, seals with large heads, and seals with no hair, to name but a few.

-Smell: The smell of a healthy seal is often difficult to describe, but is easily recognized by an experienced hunter. A healthy seal has a "fresh meat aroma" that is noticeable as soon as the animal is butchered. Unhealthy seals often smell like oil, fuel or like aged meat. Older seals have a more pungent smell than younger seals, thereby earning the name "stinky, old seals".

-Colour of meat, blubber and blood: The meat (or sinew) of a healthy seal is dark $\mathrm{red} / \mathrm{black}$. The blubber of a healthy seal is thick and white. Conversely, the meat of an unhealthy seal may appear purplish or may have infections; the blubber of an unhealthy seal may be thin and yellowish surrounded by a milky liquid. A healthy seal will have rich, dark blood.

-Taste: A healthy seal will taste fresh, whereas an unhealthy seal will taste rotten. 
Unhealthy animals are left alone for "nature to take its course", a practice that is passed from one generation to the next. Elders spoke often of the importance of teaching this to younger, less experienced hunters:

There is a saying, if you catch something that isn't right you leave it alone. (Inuit Elder, Cape Dorset, 2006)

I tell younger hunters that if they catch an unhealthy animal they should leave it alone and tell someone about it. You might catch a disease from it. Better to leave it alone to be safe, it might be contagious. (Inuit Elder, Cape Dorset, 2006)

\subsubsection{Benefits of Ringed Seal to Inuit Physical, Emotional, Social and Cultural Health}

Residents of Cape Dorset report numerous physical, psychological and cultural benefits that result from seal hunting. Seal hunting is an ancient tradition that has been passed down from generation to generation, and is therefore, an integral part of Inuit culture. Participants explained that hunting seal is part of the Inuit way of life, and is a practice that keeps Inuit culture alive. As one participant simply put it "Inuit need it". It is an activity that brings different generations of Inuit together, as more experienced hunters pass along their traditional knowledge to younger, less experienced hunters.

Hunting and sharing seal are important parts of community life. Whether the seal is shared in the home or at a community feast the significance is the same; people are 
brought together by country food. It is an age old tradition that strengthens family as well as community ties.

No parts of the seal are wasted. Seal parts that have not been consumed, go on to feed the dogs in the community. Sealskins are used to make traditional clothing, such as, amautik (traditional women's parka used to carry a baby on the mother's back), kamiit (traditional boots), jackets and mitts. Bones are made into traditional toys. The traditional knowledge and skills of how to prepare and sew with sealskins, and make traditional toys, are passed down from generation to generation:

Sealskin is very good for clothing. I don't think that making clothing from sealskin will ever disappear. I can make kamiitts and waterproof mitts out of sealskin. It will around for a long time. Even the bones of seal can be used to make traditional toys. Seal rib can be used as a drill. Different bones, like the bottom bones, can be used as toys that look like dogs. I used to play with traditional toys when I was a child. Nowadays they are just used in displays at school. But, when we go camping I show the kids how to make toys with bones so they can take them home. (Inuit Elder, Cape Dorset, 2006)

Participants report that consuming seal meat is the healthiest and most nutritious food, because it comes straight from the Earth; it is a wild meat that has not been processed in any way. In terms of physical benefits, participants widely report that consuming seal makes them feel stronger and more active. Participants report that consuming seal meat and blood keeps the body warm and provides energy. This property 
is especially important during the cold winter months and when travelling or hunting on the land. Participants report that drinking seal blood creates more blood within the individual that consumes it. In addition to the physical benefits of this traditional food source, participants state the medicinal properties of seal. It is considered to be one of the best traditional medicines for those with illness, such as the stomach flu:

Seal is very healthy to eat. Seal is not raised on a farm; it is a wild animal, without any chemicals added, meat from the wild. Fat off the seal is one of the best medicines for sickness or stomach flu. Your body will work a lot better. Especially in winter, it is the best time to eat seal because they keep you warm; especially if you drink the blood of the seal. (Inuit Elder, Cape Dorset, 2006)

In terms of psychological benefits, participants report that after consuming seal they are more relaxed and sleepy. In contrast, seal has also been credited for making individuals feel more mentally alert. Participants reported having strong cravings for seal. They also report that if Inuit could not have seal this would be a great loss and problems would follow. Seal hunting is a tradition that Inuit in Cape Dorset consider to be an integral part of their identity that they do not want to lose:

Seals are very important because we still use it. We still use sealskin like the old times. Seal hunting is a very important tradition to keep going. Seal keeps us warm, it provides us with clothing, and it's healthy. Seal hunting has been a 
tradition all these years. I don't want to lose that tradition. (Inuit hunter, Cape Dorset, 2006)

Seal hunting is important. Elders need it, and Inuit men and women need it. If a person was not feeling well, they would feel a lot better after eating seal meat. Seal meat makes the body a lot stronger. I don't think that seal will disappear. Every generation needs seal. There would be problems if Inuit stopped eating seal meat, or if there stopped being seal meat. All Inuit would crave seal meat. (Inuit hunter, Cape Dorset, 2006)

\subsubsection{Changes in Ringed Seal Health}

As previously discussed in Chapter 2, ringed seal is a vitally important animal, not only for its position in the Arctic marine food chain, but as an important subsistence food source and socio-cultural symbol for Inuit. The following section documents Inuit observations of changes to ringed seal health in response to recent environmental change in the Cape Dorset area.

Hunters in Cape Dorset are confident that ringed seals in the area are in healthy condition and are good to eat. There have been few reported case of seals with abnormalities or diseases, and such occurrences are considered infrequent. The majority of hunters report little or no changes to the availability of ringed seals in the area. However, three hunters did report that the number of seals has declined over time: 
The seals seem to be safe. But there seems to be less in the winter. (Inuit Elder, Cape Dorset, 2006)

In the last few years I've seen less seals than years ago. Years ago there were hundreds of seals, but they have declined since I was a child. (Inuit Elder, Cape Dorset, 2006)

There were barely any seals around here last year. That's unusual. There used to be lots. I don't know why there are less now. (Inuit hunter, Cape Dorset, 2006)

While the majority of hunters interviewed report the ringed seal population in the Cape Dorset area to be healthy, there have been observed changes to ringed seal body condition at the individual level. More than half of all hunters interviewed reported observing changes in the body condition of ringed seals in the Cape Dorset area. Hunters report observing ringed seals that were thinner, and in some cases, smaller (i.e. shorter) than are normally observed:

I have seen some seals that are thinner. This year I saw a few that were thinner; about $1 / 4$ of the seals I saw. (Inuit hunter, Cape Dorset, 2006)

Yes, the seals seem skinner and smaller than years before. (Inuit hunter, Cape Dorset, 2006) 
I wanted to catch a seal but it was too small. Most of the seals around here are smaller in length. The seals seem smaller than they used to be. (Inuit hunter, Cape Dorset, 2006)

Hunters explained this change in the body condition of ringed seals as a cyclical, seasonal fluctuation. During the summer months of June, July and August ringed seals are much thinner than they are in the fall. Hunters know that the seals are thinner because there are a significantly larger number of seals that sink when shot during the summer than in the fall. However, by the time fall arrives, ringed seals rebuild their layer of fat and tend to sink less often, thereby making them easier to hunt:

In June, July and August the seals are the thinnest. In fall different fur starts to grow. Sometimes the seal will go through a cycle of not eating to lose weight or to give birth to a pup. The thickness of fat is very small in June and July but in November the blubber gets three inches thick. (Inuit Elder, Cape Dorset, 2006)

The last time I went hunting, I shot a seal and right when I shot it, it sank. Sometimes they do that. There isn't enough fat on them so they sink. In the summertime they sink. By the time summer passes they float for longer. (Inuit hunter, Cape Dorset, 2006)

While this seasonal fluctuation in body fat is expected, the loss of body fat appears to be more exaggerated than previously observed. In addition, it is interesting to 
note that while the overall observed trend, was that the availability of seals has not changed, the majority of hunters report that it has become increasingly difficult to hunt seals. Various reasons were given to explain why seals were harder to hunt these days. Some hunters report that seals have become smarter and purposely hide from hunters. Others report that there are less ringed seal in the area because they have been scared off by migrating killer and bowhead whales, as well as by polar bears. One Elder believed that there were less ringed seal in the area was due to over-hunting by younger, unskilled hunters. However, the most common response for why the seals were harder to catch was because they sink more often due to reduced body fat:

They are skinny. When I hit a seal, it sinks right away. (Inuit hunter, Cape Dorset, 2006)

It looks like they sink faster these days. At this time of the year I shot at more seals that sink than I actually catch. (Inuit hunter, Cape Dorset, 2006)

It is harder to catch seals, though, because they are sinking more. It's because they have less fat. They have been sinking all summer actually. We've lost more seals to sinking than we have caught. (Inuit hunter, Cape Dorset, 2006)

Once you hit it, you have to go over to the seal right away. If you don't you are out of luck. (Inuit hunter, Cape Dorset, 2006) 
In addition to the numerous reports of thin, sinking seals, one hunter spoke of a ringed seal that he had discovered on the beach lifeless and rotting in the sun. Exhaustion could be another potential indicator of poor body condition:

It looked like might have been out in the sun for a couple of days. Nothing was wrong with the fat or the meat, it might have been on the rocks for too long (i.e. rotten). Sometimes seals will go out on the beach to get some sun or the seal will be running from an animal. Some seals spend more time on the beach than others. See more of that, more seals resting more often on the beach, because there is no ice for them to rest on. The seals might be tired. (Inuit hunter, Cape Dorset, 2006) 


\section{Chapter 5}

\section{Results}

\subsection{Impacts and Adaptation in Response to Environmental Change in Cape Dorset, Nunavut}

Chapter 4 provided a detailed account of Inuit observations of environmental change in the Cape Dorset area, specifically, changes in sea ice, weather patterns and ringed seal body condition. The following chapter will focus on detailing the impacts of these environmental changes on the lifestyles and livelihoods of Cape Dorset residents, and the adaptive strategies that have developed in response to change.

\subsection{Impacts of Changes in Weather on Lifestyle}

Recent changes in weather patterns have impacted the residents of Cape Dorset in several ways. Warmer temperatures are widely reported by residents during both the summer and winter months. The consequences of mildly warmer temperatures are not always negative. In the words of one participant, "it's a good thing and bad thing". Residents also report warmer temperatures have certain advantages. For example, residents who prefer mild temperatures have the opportunity to spend time outdoors. However, when temperatures become higher and more intense, as is being experienced during the summer months, residents report several negative impacts. For instance, participants report increased cases of sunburns and skin rashes, due to increasingly intense exposure to sun and heat. Participants also report an increasing number of people suffering from illness from heat, and eye problems from exposure to a harsher sun: 
It does seem hotter in the summer. It's a good and bad thing. People can go out for a picnic when it's hot. It's bad because some of our people are getting sick. People get sick from the heat, because it is too hot. Or sometimes someone eats bad meat that stayed out in the sun too long and gets sick. (Inuit hunter, Cape Dorset, 2006)

People have more colds and skin rashes since I've heard about climate change, more so than years ago. (Inuit hunter, Cape Dorset, 2006)

Participants report opting to stay indoors to avoid the heat when temperatures exceed the mild and become "too hot". Even when camping, participants report having to wait until the evening to do activities, in order to minimize their exposure to the intense summer heat and sun, thereby limiting their time out on the land:

This summer there were hot days, and that were really hot. Even when we went camping we would do things overnight, instead of doing them during the day, because it was too hot. We couldn't go outside, because it was too hot. (Inuit hunter, Cape Dorset, 2006)

Stronger winds have also negatively impacted residents. Stronger winds are perceived as being responsible for eroding sea ice, reducing snow accumulation, and rapidly changing, unpredictable weather. Hunters report having an increasingly difficult 
time accurately predicting the weather, which has subsequently affected planning for trips out on the land:

Winds come from all different directions. Bad weather comes more sudden without warning. Looking at the clouds right now would be able to predict that it would rain later. But today's clouds are harder to predict weather from, not like they used to be. (Inuit Elder, Cape Dorset, 2006)

There would be more hunters going out on the land, but they are hesitant because if it is nice in the morning they can't trust the forecast and they might get stuck on the land for a couple of days. (Inuit Elder, Cape Dorset, 2006)

\subsection{Impacts of Changes in Sea Ice to Livelihood}

Recently observed changes to sea ice in the Cape Dorset area have impacted residents in several ways. Sea ice is incredibly important to Inuit lifestyle, as it provides the platform on which residents travel, hunt, and pass along traditional knowledge. The reliability and safety of sea ice is, therefore, of the utmost importance if traditional lifestyles are to be maintained. As discussed in Chapter 4, residents are now reporting drastic changes to the thickness, strength and stability of sea ice in the Cape Dorset area. Consequently, residents have become increasingly wary of travelling and hunting on sea ice. When asked to describe the safety of sea ice participants often used words such as "dangerous" and "not like it used to be". 
The increasingly unsafe sea ice conditions have made residents fearful and cautious. Elders increasingly warn younger hunters to avoid certain areas for safety reasons. The floe edge, in particular, is no longer perceived as a safe place to hunt. Participants report with anxiety, near accidents on the unstable sea ice:

The floe edge was dangerous. You could see ice, water then ice...it makes it dangerous. I've heard of a man trying to cross an inlet, and as he was crossing it was breaking underneath him. (Inuit hunter, Cape Dorset, 2006)

When my partner went hunting, they almost fell once and almost lost the snowmobile because the ice was so thin. That was scary. (Inuit hunter, Cape Dorset, 2006)

Changes in sea ice and weather conditions have made it increasingly difficult for residents' to travel traditional routes, especially during the spring. Young and experienced hunters alike, have to abandon familiar trails in search of new, safer routes. Some less experienced hunters report being unsure of what alternative trails to use. Consequently, hunters report that they must invest more time, energy and resources in longer hunting trips. This is true for hunters that use snowmobiles, dog sleds and who walk to hunting sites. Hunters with access to snowmobiles report that longer hunting trips are harder on their machines, and require repairs more frequently: 
We had to use land trails instead of being able to cross the ice because there was none. It leads to longer hunting trips; we needed more gas and it was harder on the machines. There are more machine problems because of the humidity-ice in the engine causes it to seize. It happened all the time this winter. I've had to rebuild the engine, replace parts. (Inuit hunter, Cape Dorset, 2006)

Changes to the timing of sea ice break-up and freeze-up have resulted in a prolonged ice-free period. Hunters report having in less time overall to hunt out on the ice and less time to use their snow machines:

I have to wait for the ice to freeze so I can take the snowmobile out. We wait longer to get out. (Inuit hunter, Cape Dorset, 2006)

It was unusual for the ice to melt so early. We have less time to go fishing by snow machine because of climate change. (Inuit hunter, Cape Dorset, 2006)

There used to be more skidooing time and now we only have a few months, it looks like. I usually go snowmobiling until around June $20^{\text {th }}$ or something, but this year it was a lot shorter and you couldn't go as far. (Inuit hunter, Cape Dorset, 2006)

The unsafe and unpredictable sea ice has a profound impact on residents, because they are not able to get out on the land to hunt, as they need and want. As a result, they 
have limited access to country food, a reality that has created anxiety and frustration within the community:

Just last year the ice melted a whole month early. Nobody was getting any country food of any kind because there was too much broken ice. You couldn't get out on a snowmobile or anything. (Inuit hunter, Cape Dorset, 2006)

When the ice melted earlier, it affected me because I was scared that I couldn't go fishing anymore. (Inuit hunter, Cape Dorset, 2006)

Lots of people that go hunting and camping; it affects them. (Inuit hunter, Cape Dorset, 2006)

\subsection{Impacts of Changes in Weather and Sea Ice Conditions on the Health of Ringed} Seals

The recent environmental changes in the Cape Dorset area appear to be impacting both residents, and the local ringed seal population. As discussed in previous sections, residents widely report changes to the thickness, stability, and extent of sea ice in the area. Residents also report of warmer temperature and stronger winds, which are also perceived as responsible for changes in sea ice conditions. Over half of participants reported that these recent environmental changes may negatively impact ringed seals in the Cape Dorset area, although, many were unsure of exactly how. Participants report that environmental change is affecting seal body condition, reproduction and behaviour. 
I think that climate change can affect the health of the seals. They aren't as fat as I used to see them. It's hard to answer why. (Inuit hunter, Cape Dorset, 2006)

The hotter water causes furs to get thinner. I've noticed that on the seals that I have been catching. (Inuit hunter, Cape Dorset, 2006)

I think climate change, can affect the health of seals because the ice is starting to go faster. It might affect the pups. (Inuit hunter, Cape Dorset, 2006)

I think a changing climate will affect the seals. All the seals are moving into open areas, because it is cooler in the open water. Seals that go close to land to give birth or to raise young then go back to the open water. (Inuit hunter, Cape Dorset, 2006)

In contrast, one participant believed that seals in the area are happier in warmer weather:

Even the seals are happier now because of the warmer weather. Seals are happy in warmer weather. They tend to be on the ice but prefer to be in warmer areas. (Inuit Elder, Cape Dorset, 2006)

Even in the face of recent environmental change, participants were confident that seal would remain a vital part of Inuit life, as it has been for thousand of years. Participants expressed equal confidence in the ability of Inuit to adapt to changing circumstances: 
I don't think that seal will disappear. Every generation needs seal. There would be problems if Inuit stopped eating seal meat, or if there stopped being seal meat. All Inuit would crave seal meat. (Inuit hunter, Cape Dorset, 2006)

If we run out of seals for some reason, we would probably turn to caribou and other mammals. People around here are very good at adjusting to different changes, so I think that people here will be able to adapt to whatever changes that come. (Inuit hunter, Cape Dorset, 2006)

\subsection{Coping with Recent Environmental Change Through Adaptation}

Residents have developed various adaptive strategies to cope with recent environmental change. Simple coping mechanisms include changing the time of day at which residents conduct outdoor activities, in order to avoid unfavourable weather conditions, such as intense sun and heat. More complex strategies involve actively searching for new, safer trails when traditionally used trails are inaccessible. Hunters report travelling on inland routes more frequently as opposed to travelling along increasingly unreliable and unsafe coastal routes. Since the navigability of familiar trails have become unpredictable, hunters report preparing for the unexpected, which sometimes means hunting with additional equipment, for example, with both a snowmobile and a boat: 
The ice seems thinner. It makes it harder to travel. We have to change the trails we use. We had to use trails that were inland. You can take your canoe part of the way and your snow mobile part of the way. (Inuit hunter, Cape Dorset, 2006)

Hunters report changing the way they plan and prepare for hunting and camping trips. Searching for new inland routes often prolongs the length of hunting trips, and hunters must be prepared accordingly. Often this means packing additional supplies, such more fuel for snowmobiles. Hunters report being increasingly concerned with safety when on the land. Hunters that once preferred to hunt alone, now prefer to hunt in groups should something go wrong. Hunters also report listening attentively to the warnings of Elders and other community members. For example, Elders often warn against travelling in areas with strong ocean currents, such as the floe edge, as these areas have weakened sea ice:

It changes what I have to pack for trips. I used to go out hunting alone, but now I have to go out with people for safety reasons. Sometimes I don't trust the ice. (Inuit hunter, Cape Dorset, 2006)

It has changed the way that I plan hunting trips. I prepare more for hunting trips, safety-wise. I look out for more danger zones now. Elders tell us, not to go where the currents are strong. I take more supplies. I have to take more gas because I have to go by inland more. (Inuit hunter, Cape Dorset, 2006) 
I have noticed the way that people have changed, even publicly informing young people not to go out because it is dangerous, and to avoid the floe edge because of danger. (Inuit Elder, Cape Dorset, 2006)

Those that did not have access to a dog sled or snowmobile, but rather traveled by foot to hunting sites near the community, tended to opt to stay indoors when they perceived sea ice conditions to be unsafe or the weather unfavourable:

When the ice is thin, I don't want to fall so I don't go out. There are trails that I can't take anymore because the ice melts too early. (Inuit hunter, Cape Dorset, 2006)

I didn't go fishing when the ice was frozen because I didn't think it was safe. I worry about it. Like I won't know where to go, and what trails to use. Now I don't usually go out. If I had a machine I would. (Inuit hunter, Cape Dorset, 2006)

\subsection{Local Perspectives of Recent Environmental Change}

Residents of Cape Dorset widely reported that their environment has changed significantly since they were children. When participants were asked if environmental change caused them to be concerned about the future, responses varied from being very concerned, to not being concerned at all.

Participants had various ways to explain and understand recently observed changes. One participant perceived the Earth as in a continuous state of flux. Change is a 
part of life, and cannot be stopped. Another participant explained the recent changes to be part of a natural cycle of change, and was therefore nothing to worry about. Climate was returning to the way he remembered as a child:

I've noticed a lot of changes. The world is always changing. Climate change doesn't worry me; that's the way the earth is. It is always going to change, and there is nothing we can do to stop it. (Inuit Elder, Cape Dorset, 2006)

I don't believe what other people say about pollution changing the weather around us. I don't worry about climate change. I'm glad that the weather that I had when I was a child is coming back. Every 50 years or so warm spells happen and that has been going on for as long as I can remember. It is because every 50 years of so the Earth moves closer or further away from the sun, and that leads to warming and cooling. It is part of a natural cycle. The last 50 years has been cooler but the next 50 years will be warmer. Hot is part of the cycle. (Inuit Elder, Cape Dorset, 2006)

In contrast, over half of participants expressed deep concern about the impacts of environmental change (often referred to as climate change) on their livelihoods. Participants expressed concern about how environmental change has already impacted their lives, and affected their knowledge of their surroundings. Participants were unsure of what changes to expect in the future, but feared that Inuit traditional activities may be at risk: 
I worry about climate change; I wonder if the ice is going to freeze this year, or how long it will stay. (Inuit hunter, Cape Dorset, 2006)

I think that climate change has an affect on everything. I think that climate change might impact Inuit traditional activities. It changes the thickness of the ice. It makes it not strong. It has changed how we travel. The weather is harder to predict. (Inuit hunter, Cape Dorset, 2006)

I think that maybe every Inuit person might be worried about climate change. (Inuit hunter, Cape Dorset, 2006)

When asked to describe the environmental changes they had observed, many participants were reminded of stories they were told by Elders, warning of changes to come. Participants were shocked to be experiencing the changes their Elders spoke of in years past. Other participants spoke of not being concerned for themselves, but rather for the future generations that will have to deal with greater change:

The climate has definitely changed. My grandparent told me that in later years, up here in the North, there wouldn't be snow falling anymore, and here I am witnessing it. Even before people traveled to the North, people have lived here for thousands of years. The stories are passed along. Stories told from years ago eventually come true. (Inuit Elder, Cape Dorset, 2006) 
I'm not worried about changes. When we are no longer around, it will be the time to worry. Future generations will have something to worry about. (Inuit Elder, Cape Dorset, 2006)

Yes, the climate has changed since I was a child. It has become more unpredictable. The weather fluctuates a lot. I don't worry for myself but I worry for my son. Is he going to be able to do the things that I do now? (Inuit hunter, Cape Dorset, 2006)

Some participants expressed a mixture of worry and apathy when asked about the impact of environmental change. While they acknowledge that change has occurred, the forces at work seem out of their control. Participants perceive more times of hardship for Inuit in the future. Some are unsure of how Inuit will deal with these changes. Others chose not to worry until faced with the changes:

It doesn't worry me because I can't do anything about it. I bet that everybody will hardly go out on the land if the weather changes so much. It makes me feel sad, it's changed so much. I don't know if Inuit will be able to adapt to the changes. (Inuit hunter, Cape Dorset, 2006)

I have seen drastic changes since I was a child. I'm not really concerned about climate change, but I have noticed quite a bit of change. There will probably be more drastic changes in the future. I'm not sure what changes are coming. There 
will be more hardship for the Inuit up North. There will be changes. I try not to worry about it today. When it comes, I'll deal with it. (Inuit hunter, Cape Dorset, 2006) 


\section{Chapter 6}

\section{Discussion}

\subsection{The Direct and Indirect Impacts of Environmental Change on Human and Environmental Health in Cape Dorset, Nunavut}

As documented in the numerous direct statements from residents of Cape Dorset, Nunavut, Inuit in this region are observing various changes in their environment, including changes weather patterns, sea ice conditions, and the health of wildlife, such as ringed seals. These environmental changes are beginning to impact the Inuit way of life and as a result, are putting Inuit physical, social and cultural health at risk.

The environmental changes presented in this study will be considered in terms of their direct and indirect impacts on human health and wellbeing (ACIA, 2005). Direct impacts refer to those health consequences resulting from direct interactions with aspects of the environment that have changed or are changing with local climate (Furgal et al., 2002 in Krupnik and Jolly, 2002). They include such things as difficulties in dealing with heat and cold stress; alleviation of cold stress due to warm winters; dangers associated with travel and activities on the land resulting from unpredictable weather patterns and ice conditions; and increased incidences of sunburn and rashes as a result of increased sun intensity and exposure to UV-B radiation (ACIA, 2005).

In addition to direct impacts of climate-related changes on human health, human health in northern communities is affected by a number of indirect impacts. These refer to those health consequences resulting from indirect interactions mediated via human behaviour and components of the environment that have changed or are changing in the 
local environment (Furgal et al., 2002, in Krupnik and Jolly, 2002). These indirect effects include critical impact mechanisms such as social and mental stress related to changes in the environment or lifestyle, which are related to changes in the local climatic regime. This includes such things as effect on diet (i.e. decreased subsistence/cultural food species abundance and or availability) as a result of climate-related impacts on wildlife species or environmental factors influencing indigenous peoples' access to these resources (e.g. ice distribution, landscape stability, weather predictability) (ACIA, 2005).

Several direct and indirect impacts of environmental change on human health and wellbeing were reported by local residents of Cape Dorset. For instance, in terms of direct impacts, sunburns, skin rashes, and eye problems such as snow blindness, have become common due to increased exposure to a harsher sun. Heat sickness is reported as becoming more common as residents are experiencing difficulties dealing with warmer temperatures, particularly during the summer months. Stronger and rapidly changing winds have made it difficult for hunters to accurately and confidently predict the weather. Changes in sea ice conditions and the timing of freeze-up/break-up have made travelling and hunting increasingly difficult and unsafe for residents.

In terms of indirect impacts, hunters have less time to travel and hunt on sea ice, primarily due to an increasingly prolonged ice-free period, and poorer, rapidly changing weather patterns. Less time spent on the land hunting, translates into limited access to traditional foods, which are of nutritional, economic and cultural importance to local peoples. In addition, residents have become increasingly anxious about travelling on sea ice. Many residents opt to stay indoors for reasons of personal safety, and to avoid heat and poor weather, thereby limiting their time spent on the land. This also potentially 
limits their access to traditional foods. Hunters report being hesitant to plan extended hunting trips on the land, due to recent difficulties in predicting today's rapidly changing weather. More hunters fear that if they plan extended trips to their preferred hunting grounds, many of which are further from the community, they risk being left stranded on the land for days at a time, because poor weather comes so rapidly and often without warning. Consequently, it is more common for hunters to hunt closer to the community, and at times must abandon hunting and fishing grounds that are of nutritional and personal significance.

Other indirect impacts of climate-related change to human health in northern communities involve changes to the availability of healthy traditional food sources. Climate-related environmental changes can have dramatic direct and indirect impacts on the number, distribution and health status of important traditional food sources, like the ringed seal, which may in turn have significant physical, social and cultural health effects on indigenous populations which depend on them (ACIA, 2005). It is expected that most Arctic species will migrate further north in response to climatic warming (Tynan et al., 1997). While the majority of hunters observed no significant changes to the number or distribution of ringed seals in the Cape Dorset area, three hunters did report declines in seal numbers over time.

In addition, hunters widely report that ringed seals have become thinner and increasingly difficult to hunt in open water during the summer months. Seals have become increasingly difficult to hunt in open water, because more seals sink when shot, and at a faster rate than is normally observed. This results in more seals being lost to sinking than are actually harvested during the ice-free summer months. Consequently, 
hunters must seal hunt more frequently and do not necessary reap the benefits of doing so. Hunting for seal by boat can be a lengthy process, requiring great patience and skill, a lesson that I learned first hand during a 10 hour hunting expedition. I was taken seal hunting by a highly-skilled and experienced, life-long hunter who I had met during previous trips to Cape Dorset. During our trip we encountered seven seals, five of which were shot at successfully. However, despite all our efforts we were only able to harvest one seal. The other seals we shot at sank beyond our grasp before we were able to reach them. The hunter told me that normally when he goes hunting in the fall, he is able to catch as many as fifteen seals in one day. But, it has become far more difficult during the summer. In addition to the time and energy invested by the hunter, seal hunting in open water requires resources, such as access to a boat, guns or harpoons, and money for fuel and bullets. As seal hunting during the ice-free summer months becomes more difficult hunters will continue to spend more time, energy and resources hunting for seal. For hunters with limited resources, this may be a cost that is greater than their means.

Hunters expect seals to be thinner during the summer, particularly during the months of June, July and August. However, this change in body condition appears to be more exaggerated than is typically observed. Ringed seals may be responding to recent changes in sea ice extent, depth and stability in the Cape Dorset area. The explanation of this may be linked to the integrity of the Arctic marine food chain, and more specifically to the ice edge community upon which it is based. It is well recognized that ice algae play an important role in sustaining the secondary production that supports marine mammals in the Arctic (Tynan et al., 1997). For example, dense algal mats support a sympagic community that includes crustaceans, such as the pelagic amphipod, Parathemisto 
libellula, and cryopelagic fishes, such as Arctic cod (Boreogadus saida) upon which marine mammals feed (Tynan et al., 1997). In the eastern Canadian Arctic, ringed seals inhabiting the pack ice of Baffin Bay feed extensively on P.libellula in addition to feeding on Arctic cod (Finley et al., 1983). It is expected that changes in sea ice, water temperature, freshwater input, and wind stress will affect the rate of nutrient supply in the Arctic Ocean, due to their effect on vertical mixing and upwelling. Changes in vertical mixing and upwelling are expected to affect the timing, location, and species composition of phytoplankton blooms. This will in turn affect the zooplankton community, the productivity of fish, and consequently the health of higher sea mammals (ACIA, 2005). It is possible that due to changes in sea ice and the length of the ice-free period, ringed seals in the Cape Dorset area are not able to adequately feed on their preferred prey items, and therefore must consume less energetically valuable alternatives. This may lead to poorer body condition than is normally observed during the summer months. In other words, because their preferred prey items are not available, seals are not able to build up adequate fat reserves, resulting in them being much thinner in the surnmer than is normally observed. The lack of body fat results in reduced buoyancy, which results in more seals sinking in open water when shot by hunters, thereby making seals more difficult to hunt.

Similar observations were made by Inuvialuit hunters from the community of Sachs Harbour in the western Canadian Arctic (Riedlinger and Berkes, 2001). Hunters report that seals are sinking to a deeper water level at the flow edge, phenomena attributed to a lower fat content and/or the greater freshening of the ocean water from melting ice. In late winter, seals tend to be relatively low in fat and the spring-melt results 
in low density surface waters, hence, seals are less buoyant and tend to sink deeper. The authors proposed that the fact that seals in recent years are sinking deeper may be local evidence that the low-salinity surface layer has become thicker, but did not discuss the possibility that seals themselves may be in poorer condition. In addition, while only one hunter reported finding a seal rotting on the beach, this observation might be an indication of further physical stress brought on by poor body condition. It is possible that the reduced body condition of seals during the summer may be contributing to exhaustion, as seals my not have adequate energy reserves to swim and forage in open water. If warming in the Arctic region continues, as is suggested by a growing body of literature, we can expect further changes to the extent and concentration of sea ice, length of the ice-free period, and composition of the ice-edge community, all of which may negatively impact the health of ringed seals.

While examining the composition and integrity of the marine food chain was not the focus of this study, it remains an important direction for future research activities, if we are to understand all the environmental stresses that may be negatively impacting the health of ringed seals. In addition, community-based monitoring of the body condition ringed seals in the Cape Dorset area remains an important aspect of research, in order to establish baseline data with which to compare future change.

\subsection{The Importance of Examining Health and Place in the Context of Environmental Change}

The study of therapeutic landscapes demonstrates the importance of places for maintaining physical, emotional, mental and spiritual health. Wilson (2003) was the first 
to broaden the analysis of therapeutic landscapes by exploring their culturally specific dimensions in the context of the everyday lives of "Anishinabek" (Ojibway and Odawa) First Nations peoples. While geographic research had explored First Nations health, few studies had attempted to explore the influence of cultural beliefs and values on health, let alone the intricate link between the land and health. Interviews revealed that for Anishinabek, the land represented more than just a physical or symbolic location of healing. Instead, the land represented a complex intersection of culture, identity and health. Her findings demonstrated that culture is an important component of the link between health and place in everyday life. Recent work by Donaldson (2007) established similar significance for Inuit in the community of Cape Dorset, Nunavut. I was fortunate to participate in this study as a field assistant, and while conducting interviews with women in the community gained a deeper appreciation for the significance of the land to Inuit health and wellbeing.

Inuit culture has developed in close relationship with the land. The land is a comprehensive concept of the environment that refers to plants, animals, and humans as well as the physical environment. The land is a source of livelihood and a basis for Inuit culture, and has been at the centre of Inuit identity, spirituality and morality. Values and ethics such as sharing and respect for wildlife are beliefs that have been passed down and are still in force in modern Inuit culture. The land provides Inuit with many traditional foods which are nutritionally, socio-economically, and culturally significant. The land also represents a place where traditional knowledge is created, accumulated and passed along from generation to generation. It is for these many reasons that the land, as place, is so significant to the health and wellbeing of Inuit. But, as the Arctic environment 
continues to change, so too will the relationship of Inuit to the land. What has

traditionally been a place conducive to health and wellbeing may become increasingly unhealthy.

Researchers are beginning to recognize that understanding the importance of environmental change in contributing to Inuit health is critical, and yet remains a poorly understood area of research (Krupnik and Jolly, 2002). Similarly, understanding the relationship between health and the land (as place) to Inuit health in the context of environmental change is poorly understood, but will become increasingly important as environmental change in the Canadian Arctic continues, as is predicted.

Many health issues potentially influenced by environmental change are becoming increasingly prevalent in northern communities today. For instance, the physical, social and cultural importance of ringed seal as a source of country food makes the potential threats of environmental change to food security extremely significant. Harvesting ringed seal is still actively pursued and remains a vital part of Inuit culture today. Participants in this study expressed difficulty imagining a future without seal, and felt that seal would always be part of Inuit life, as it has been for generations.

While the nutritional importance of seal cannot be understated, its significance to Inuit culture goes beyond mere physical sustenance. Harvesting, preparing and sharing seal is an integral part of Inuit cultural identity and spirituality (Peter et al., 2002). It is through the communal sharing of seal that Inuit regain their physical, mental and cultural strength. It is a practice that links present day Inuit to their ancestors, through a longstanding tradition, that has been passed down from generation to generation for thousands of years (Borre, 1994). It is therefore important in terms of individual and 
community health to properly identify and understand the impacts of environmental change that may influence the health, availability or accessibility of important country food species, like the ringed seal.

In addition, Arctic populations have much higher rates of mortality resulting from unintentional or accidental injury (ACIA, 2005). If conditions on the land continue to become unsafe, what has traditionally been a place conducive to health and wellbeing may become increasingly unsafe, and therefore, unhealthy for individuals (Donaldson, 2007). Participants interviewed in this study spoke of how sea ice in the area has become increasingly unsafe and difficult to travel. Participants also spoke of the increasing occurrence of accidents on the ice. It may become increasingly important for health care professionals to recognize the relationship between environmental change and injuries causing death (Furgal et al., in Krupnik and Jolly, 200்2).

Environmental change may also impact the emotional health and wellbeing of Inuit. How Inuit relate to a changing environment emotionally, culturally, and spiritually is an important aspect of health and place research that has not been adequately addressed. Fox (2002, in Krupnik and Jolly, 2002) uses the example of how many extremely skilled elders and hunters can no longer predict the weather as they have in the past. No longer able to be confident in their predictions, some elders and hunters are genuinely distressed, not only because they can no longer advise travel parties with assurance, but because their personal relationship with the land and the weather itself has changed. Hunters and elders from Cape Dorset told similar stories, about not being able to predict the weather with confidence or not being able determine if a certain trail was safe to travel. These uncertainties have become sources of stress for residents in Cape 
Dorset. Emotional responses to environmental change are often linked to feelings of identity (Fox, 2002 in Krupnik and Jolly, 2002). Residents of Cape Dorset spoke passionately of the importance of being on the land and of hunting seal to Inuit cultural identity (Donaldson, 2007; This thesis). One participant even predicted that if for some reason seal became scarce there would problems for the people of Cape Dorset.

Based on the many examples presented in this thesis, it is clear that the land represents far more than just a physical place to Inuit. The findings demonstrate the complex relationship between Inuit and the land, which is closely linked to feelings of identity, and all aspects of health and wellbeing. What is novel about this research is that it examines the relationship between Inuit health and the land in the context of environmental change. As the land changes in unfamiliar and unpredictable ways, so too will the relationship of Inuit to the land. As a result the physical, emotional, spiritual and cultural health of Inuit may be at risk.

\subsection{Coping with the Impacts of Environmental Change}

The Inuit of Nunavut are the descendents of ancient peoples who survived in Canada's harsh northern climate, by following the resources of the land and sea from season to season (Kristifferson and Berkes 2005, in Berkes et al., 2005). The continued existence of Inuit in Canada's North is proof that their traditional way of life, based on developing an intimate knowledge and relationship with the land, is indeed successful. However, the twentieth century has lead to an end of the traditional Inuit nomadic lifestyle. The contemporary Inuit are primarily located in settlements and live in a mixed economy that consists of wage employments, transfer payments, and subsistence resource 
harvesting (Kristofferson and Berkes, 2005, in Berkes et al., 2005). While dealing with environmental change is nothing new for Inuit, nature's constant state of flux has accelerated, such that, environmental change is described by one Cape Dorset Elder as "not like it used to be". Such changes alter the quantity and quality of environmental resources, thereby diminishing the sustainability of northern indigenous communities. Dependence on a compromised local physical environment, without adequate wealth to import resources from elsewhere, limits options for survival. Inuit communities in Nunavut are vulnerable to rapid changes, as their coping capacity is limited by poverty and minimal infrastructure (Myers et al., 2005, in Berkes et al., 2005).

Human dimensions of change, including planning for and understanding human adaptation, is an important aspect of environmental change research, but is poorly understood (IPCC, 2001). Including traditional knowledge in adaptation research can establish the changes that members of the community observe, how the changes are perceived, and how changes impact livelihoods (Riedlinger and Berkes, 2001).

The relationship between Inuit and the Arctic environment is closely tied to cycles of seasonal activity and resource use. Environmental change is part of daily life for Inuit, and a capacity to adapt to changing conditions is part of livelihood systems. However, unexpected or extreme events and unusual fluctuations create hardships because they interfere with the ability of people to access the various resources on the land, and make resource availability itself less predictable (Fast and Berkes, 1998). Climate change, at rates outside of the historical experience, may also make some aspects of traditional knowledge unreliable. For example, many Cape Dorset hunters are no longer confident in their ability to accurately predict the weather because of recent changes in wind strength 
and clouds in the area. How much change can be accommodated by the current system of traditional knowledge and practice? The amount of perturbation that a system can absorb and to which it can adapt is a measure of the resilience (or flexibility) of that system. In areas experiencing social and environmental transformations, such as the Canadian North, there is a need to develop the capacity to respond to and adapt to change (Berkes et al., 2005). The concept of resilience provides a window for the study of change. The resilience of a system is defined in terms of: (1) the magnitude of shock that a system can absorb and still remain within a given state, or the ability to buffer disturbance; (2) the self-organization capability of that system; and (3) its capacity for learning and experimentation (Folke et al., 2002; Berkes et al., 2005). The question of resilience is important because little is known about the cultural, social and economic limits to adaptability.

Inuit in Nunavut are learning to cope with the impacts of climate change in a number of inventive ways, at the individual and community level. Residents of Cape Dorset have developed various adaptive strategies to cope with recently observed environmental changes, thereby, exhibiting their capacity to respond and adapt to change. Many residents have modified their own behaviour in order to avoid situations that may put their health at risk. For example, in order to avoid exposure to increasingly hot temperatures and the subsequent impacts (i.e. sunburns, rashes, heat sickness, etc) many residents have changed the time of day they plan outdoor activities. However, staying indoors comes with the disadvantage of spending less time spent on the land.

Inuit in Cape Dorset are also coping with change by modifying their subsistence strategies and practices. Many hunters actively seek out new, inland hunting trails when 
traditionally used coastal routes are inaccessible or deemed unsafe. Solitary hunters are now more inclined to travel in groups when on the land, as there is safety in numbers should an accident occur when hunting on the unstable sea ice, or if caught in bad weather. Hunters have changed the way they plan and prepare for hunting trips. Trips on the land have become increasingly long, due to unexpected obstacles, such as inaccessible trails and poor weather. Hunters have learned to deal with uncertainty by preparing for the unexpected, which often entails packing additional equipment, supplies and fuel. Before travelling on the land hunters pay close attention to weather forecasts, announcements on the community radio and the advise of other hunters and Elders as a way of gathering information about conditions on the land. By sharing information hunters are able to avoid dangerous terrain, thereby limiting the potential for accidents. Witnessing recent environmental changes has reinforced in residents the value of patience. Whether waiting for the ice to freeze or for bad weather or hot temperatures to pass, residents recognize that waiting for favourable conditions can minimize the number of illnesses, injuries and even deaths in the community.

While hunters did report various adaptive strategies, some residents were more vulnerable to environmental changes than others. For instance, it is interesting to note, that participants with limited resources, such as no access to a dog sled or a snowmobile, were the most vulnerable to changes in sea ice. While hunters with snowmobiles or dog sleds had the ability to change their routes (leading to albeit longer trips), residents that traveled by foot often did not have the time, energy or resources to do the same. Participants with limited resources reported more frequently that if they did not perceive the sea ice to be safe, they would forego travelling and hunting on the land altogether. 
Their reasons for not travelling on the sea ice were either that: (i) they were worried about their safety; (ii) they did not know what other route to take to get to their preferred hunting or fishing grounds; (iii) finding an alternative route to their preferred hunting site would be take too long by foot; (iv) they did not know of any other local hunting or fishing site that could be reached safely. Participants with limited resources missed opportunities to participate in hunting, fishing and/or recreational activities on the land. Instead, these individual would stay indoors, potentially limiting their access to traditional foods and the psychological, social and cultural benefits of being on the land.

The coping mechanisms being developed in Cape Dorset are primarily short-term strategies to deal with the day-to-day obstacles faced by residents. While residents of Cape Dorset are coping with environmental change by modifying their patterns of subsistence, many are observing changes they have never witnessed in their lifetime, and at a much faster rate of change. This lack of reference makes it increasingly difficult for residents to predict, and thus prepare for, future changes. Many are aware of how recent environmental changes have altered their lives already, and worry that more hardships lie ahead for future generations of Inuit. Even so, the majority of Cape Dorset residents believe that they will deal with environmental changes as they come, as Inuit always have.

The changes observed in Cape Dorset are not beyond the range of the community's ability to respond and cope. Residents of Cape Dorset have adjusted their subsistence activities and practices to accommodate seasonal fluctuations and change. However, these changes are relatively recent events, and how Inuit are coping and responding up to now may not be a reliable indication of the community's ability to adapt 
in the future, especially if the rate of change in the Arctic continues to increase (Riedlinger and Berkes, 2001).

\subsection{The Importance of Local Perspectives in the Study of Health and Place in the Context of Environmental Change}

Local perspectives are extremely important when attempting to understand the inter- and intra-regional variations of climatic and environmental change (Krupnik and Jolly, 2002). Furthermore, the difference between scientific models and locally based knowledge highlights the value of local, indigenous perspectives in climate-related research. An understanding of environmental and climatic changes and their impacts on individuals is necessary if northern communities — such as Cape Dorset-are to be able to adapt and evolve with the changing nature of their surroundings (Furgal et al., 2002 in Krupnik and Jolly, 2002). Many residents in Cape Dorset are observing changes in their environment for the first time, which has limited their ability to predict and thus prepare for future changes. Without the local understanding of changes and potential impacts, such as those discussed in this thesis, it is difficult to know the rate of changes experienced in northern communities to date, thereby limiting the predictive ability of knowing what to expect in the future. The key to understanding the impacts of climate change on northern communities is through the perspective of northern people.

Awareness of climate change in the Arctic, as described by communities themselves, may provide the necessary thrust to policy-makers and governments to plan more effectively in addressing the impacts of climate change. 
The Government of Nunavut's (GN) Nunavut Climate Change Strategy (NUCCS), which was released in 2003, is a primary example of how IQ and local observations can aid in understanding the impacts of climate change. The GN has adopted IQ as an official policy, keeping in line with its commitment to develop practices and policies that are consistent with the culture and values of Nunavummiut. The three principle goals of the NUCCS are to: 1) identify and monitor climate change impacts; 2) develop adaptation strategies; and 3) control and reduce greenhouse gas emissions. The GN is now in the process of developing the Nunavut Adaptation Plan (NAD) which is set to be released in spring 2009. The NAD emphasizes the need for appropriate and relevant northern indicators to help establish baseline data that can be used to measure rates of change. The plan also highlights the importance of developing adaptation strategies in response to the impacts of climate change. Key indicators (i.e. climatic, biological, economic, and community) have been identified to monitor all aspects of change being experienced by communities in Nunavut. The NAD emphasizes the need to build partnerships at the community, regional, national and circumpolar levels to enable Inuit to share knowledge on climate change impacts and adaptation, and to develop and implement policies designed to address the issue of climate change.

This study contributes to policy by: 1) documenting local Inuit knowledge of environmental change and changes to the health of ringed seals in Cape Dorset, Nunavut; and 2) documenting how Inuit in the community of Cape Dorset experience, cope and adapt to the impacts of environmental change. This study may present local-scale information about Inuit observations and experiences of environmental change that are 
not presently known by the GN, and therefore, may influence policy and adaptation strategies. 


\section{Chapter 7}

\section{Summary and Conclusions}

\subsection{Summary and Conclusions}

Understanding the relationship between health and the land, as place, in the context of environmental change is poorly understood. However, the implications of environmental change for Inuit physical, emotional, spiritual and cultural health and wellbeing are significant. By monitoring culturally significant aspects of the environment, such as sea ice and the health of ringed seals, it may be possible to gain a greater understanding of the role that the land plays in the health and wellbeing of Inuit.

The purpose of this study was to use Inuit Qaujimajatuqanjit to document the impacts of environmental change on sea ice and the health of ringed seals in Cape Dorset, Nunavut. The use of Inuit Qaujimajatuqanjit is gaining recognition in helping to understand Arctic environmental change, at the local-scale, in particular. This study uses a participatory or community-based approach to document Inuit observations of recent environmental change. The purpose of using a qualitative methodology for this research was ensure the full collaboration and participation between myself, as a researcher, and the residents of Cape Dorset that took part in the study.

While it is widely recognized that ringed seal play a vital role in the health and wellbeing of Inuit, to date, no studies have examined the effects of climate change on this Arctic keystone species. Inuit have a longstanding history of harvesting and utilizing seal and seal products for food and clothing. Inuit, therefore, possess an intimate and detailed local knowledge about seal, that be used to document and monitor recent change. 
The residents of Cape Dorset, Nunavut have generations of experience hunting, travelling and living in close relationship with the land. In recent years, they have witnessed numerous changes in their environment, many beyond the scope of living memory. To briefly summarize, participants report significant changes to the thickness, extent and stability of sea ice, as well as to the timing of both break-up and freeze-up. Sea ice has become increasingly difficult and unsafe to travel. In addition, residents of Cape Dorset have observed several changes in weather conditions. For example, temperatures throughout the year have increased, particularly during the summer and winter months. Prolonged hot spells are far more common during the summer, as are warm spells during the winter. An increasing number of residents suffer from sunburns, skin rashes, eye problems and heat sickness due to prolonged exposure to warm temperatures and a harsher sun. Residents have also observed changes in precipitation, and report an increase in rainfall and decrease in snowfall during the winter months. The depth, quality and texture of snow have noticeably changed in recent years. As a result, residents have difficulty constructing traditional igloos, which are used as a temporary shelter when on the land. The strength and severity of winds in the Cape Dorset area have also changed. Severe weather comes more rapidly and often without warning. Stronger, unfamiliar wind patterns have made it increasingly difficult for hunters to confidently and accurately predict the weather.

In addition to changes in sea ice and weather conditions, hunters are observing changes to the body condition of ringed seals in the Cape Dorset area. Hunters report observing ringed seals that are thinner, and in some cases shorter in length, particularly during the summer months of June, July and August. While hunters expect ringed seals to 
be at their thinnest during the summer, this seasonal fluctuation in body fat appears to be more exaggerated than previously observed. As a result, seals have become increasingly difficult to hunt in open water during the summer months. This is because more seals sink when shot and at a faster rate. More seals are being lost to sinking than are actually harvested, and as a result hunters are exhausting more time, energy and resources hunting seal during the ice-free summer months. I propose in this thesis that ringed seals may be responding to recent environmental change in the Cape Dorset area. It is possible that due to changes in sea ice and the length of the ice-free period, ringed seals in the Cape Dorset area are not able to adequately feed on their preferred prey items, and therefore must consume less energetically valuable alternatives. Seals are not able to build up adequate fat reserves, resulting in them being much thinner in the summer than is normally observed. The lack of body fat results in reduced buoyancy, which results in more seals sinking in open water when shot by hunters, thereby making seals more difficult to hunt. Recent environmental change has impacted the lifestyle and livelihoods of Cape Dorset residents. Consequently, residents have responded to change by adapting their subsistence strategies and practices. Hunters actively seek out new inland trails, when traditionally used coastal trails are inaccessible or unsafe. Hunters, even those that prefer to hunt alone, have begun travelling in groups for safety reasons. Hunters prepare for the unexpected when planning trips on the land, which often means packing additional food, clothing, equipment and fuel. Gathering and sharing information about sea ice and weather conditions has become an important way of minimizing risk when on the land. Finally, exercising patience in the face of environmental change has proved an effective way of minimizing the number of illnesses, injuries and even deaths in the community. 
The adaptive capacity demonstrated by the residents of Cape Dorset illustrates that the changes being experienced are not beyond by the community's ability to cope with and respond to change. However, these changes are relatively recent events, and how Inuit are coping and responding up to now may not be a reliable indication of the community's ability to adapt in the future, especially if the rate of change in the Arctic continues to increase.

The findings presented in the study demonstrate the importance of studying the relationship of health and the land, as place, in the context of environmental change. Based on the many examples presented in this thesis, it is clear that the land represents far more than just a physical place to Inuit. The findings demonstrate the complex relationship between Inuit and the land, which is closely linked to feelings of identity, and all aspects of health and wellbeing. As the land changes in unfamiliar and unpredictable ways, so too will the relationship of Inuit to the land. As a result the physical, emotional, spiritual and cultural health of Inuit may be at risk.

\subsection{Future Research Directions}

Examining the relationship between health and the land, as place, represents a poorly understood aspect of research. I have demonstrated in this thesis that by monitoring specific aspects of the environment, that are culturally significant, we may gain a deeper understanding of the role the land plays in the maintenance of Inuit health and wellbeing. As the Arctic landscape continues to change, understanding how changes impact the physical, emotional, spiritual and cultural aspects of Inuit health and wellbeing will continue to be an important direction for future research. 
In addition, if warming in the Arctic region continues, as is suggested by a growing body of literature, we can expect further changes to the extent and concentration of sea ice, length of the ice-free period, and composition of the ice-edge community, all of which may negatively impact the health of ringed seals. While examining the composition and integrity of the marine food chain was not the focus of this study, it remains an important direction for future research activities. If primary and secondary production is being negatively impacted by climate and environmental change, it will have consequences that will trickle up the Arctic marine food change, and may have dramatic impacts on the health of marine mammals, such as the ringed seal. Since ringed seals are the primary prey of polar bears and comprise a significant portion of the Inuit diet, studies that monitor the abundance, distribution and overall health of ringed seals are necessary.

The study of environmental change research presents a promising opportunity for collaborative inter-disciplinary research, which not only involves physical and social scientists, but also northern communities. Community-based monitoring of environmental change can provide a means of establishing baseline data, which can be used to monitor future change. Community-based programs can also serve as a means to link traditional ecological knowledge and scientific approaches, while retaining traditional knowledge in its cultural context. 


\section{References}

ACIA, 2005. Arctic Climate Impact Assessment. Cambridge University Press, 1042p.

American Society of Mammologists Committee on Marine Mammals. 1967. Standard measurements of seals. Journal of Mammology 48: 459-462.

AMAP, 2003. AMAP Assessment 2002: Human Health in the Arctic, Arctic Monitoring and Assessment Programme (AMAP), Oslo, Norway.

Andersen M, Hjelset AM, Gjertz I, Lydersen C, Gulliksen B. 1991. Growth, age at sexual maturity and condition in bearded seals (Erignathus barbatus) from Svalbard, Norway. Polar Biology 21:179-185.

Anderson, PK. 2001. Marine mammals in the next one hundred years: Twilight for a Pleistocene megafauna? Journal of Mammology 82(3): 623-629.

Aboriginal Peoples Survey 2001, http://www12.statcan.ca/english/profil01 aps/home.cfm

Beck GG, Smith TG, Hammill MO. 1993. Evaluation of body condition in the northwest Atlantic harp seal (Phoca groenladica). Canadian Journal of Fisheries and Aquatic Sciences 50:1372-1381.

Berkes, F. 1993. Traditional ecological knowledge in perspective. Published in: Traditional ecological knowledge: cases and concepts. Edited by Julian Inglis. International Program on traditional Ecological Knowledge. Ottawa, Ontario, Canada. Pg 1-7.

Berkes, F, Huebert, R, Fast, H, Manseau, M, and Diduck, A (editors). 2005. Breaking ice: renewable resource and ocean management in the Canadian north. Vol. 7. Calgary: University of Calgary Press.

Berkes, F, Bankes, N, Marschke, M, Armitage, D, and Clark, D. 2005. Cross-scale institutions and building resilience in the Canadian North. In: Berkes, F, Huebert, R, Fast, H, Manseau, M, and Diduck, A (editors). Breaking ice: renewable resource and ocean management in the Canadian north. Vol. 7. Calgary: University of Calgary Press.

Bill, L, Crozier, D, Surrendi, L, Flett, and MacDonald, D. 1996. A report of wisdom synthesized from the traditional knowledge component studies. Edmonton: Northern River Basin Study.

Borre, $\mathrm{K}$. The healing power of the seal: the meaning of Inuit health practice and belief. Arctic Anthropology 31(1): 1-15. 
Bourgeois, Jackie. 2006. Using northern indicators and Inuit Qaujimajatuqangit in the development of a Nunavut adaptation plan. Government of Nunavut. Department of Environment. (http://czc06.ca/images/PDF/1-2-A\%20Bourgeois.pdf)

Bryman, A. and Burgess, R.G. 1994. Analysing qualitative data. London; New York: Routledge.

Burga, Conradin A., Edwards, Peter J., and Walther, G. -. 2001. "Fingerprints" of climate change : adapted behaviour and shifting species ranges. New York: Kluwer Academic/Plenum Publishers.

CACAR, 2003. Contaminant Levels, Trends and Effects in the Biological Environment. Edited by A. Fisk, K. Hobbs, and D. Muir. Ottawa: Department of Indian and Affairs and Northern Development.

Chataway, CJ. 1997. An examination of the constraints on mutual inquiry in a participatory action research project. The Journal of Social Issues 53, no. 4:747-765.

Cobb, D, Berkes, MK, Berkes, F. Ecosystem-based management and marine environmental quality in northern Canada. In: Berkes, F, Huebert, R, Fast, H, Manseau, M, and Diduck, A (editors). Breaking ice: renewable resource and ocean management in the Canadian north. Vol. 7. Calgary: University of Calgary Press.

Cohen, SJ. 1997. What if and so what in northwest Canada: could climate change make a difference to the future of the Mackenzie Basin? Arctic 50(4): 293-307.

Comiso, JC. 2002. A rapidly declining perrenial sea ice cover in the Arctic. Geophysical Research Letters 29, no. 20:1956-1960.

Comiso, JC. 2003. Warming trends in the Arctic from clear-sky satellite observations. Journal of Climate 16: 3498-3510.

Cota GF, Horne EPW. 1989. Physical control of arctic ice algal production. Marine Ecology Progress Series 52: 111-121.

Davis A, Wagner JR. Who knows? On the importance of identifying "experts" when researching local ecological knowledge. 2003. Human Ecology 31(3): 436-489.

DeMaster DP, Davis R. 1995. Workshop on the use of ice-associated seals in the Bering and Chukchi sea as indicators of environmental change. Report of the workshop 
in ice-associated seals held 29-31 March 1994 at the national marine mammal laboratory, NOAA, Seattle. $10 \mathrm{p}$.

Derocher AE, Lunn NJ, Stirling A. 2004. Polar bears in a warming climate. Integrative and Comparative Biology 44: 163-176.

Donaldson, SG. 2007. The role of local renewable resources in the health and well-being of Inuit living in Cape Dorset, Nunavut, Canada. Ph.D. Thesis. Carleton University, Ottawa, Ontario, Canada.

Doubleday, NC. 1993. Finding common ground: natural law and collective wisdom. Published in: Traditional ecological knowledge: cases and concepts. Edited by Julian Inglis. International Program on traditional Ecological Knowledge. Ottawa, Ontario, Canada. Pg 41-53.

Environment Canada. The Inuit Economy: Sustaining a Way of Life. http://www.ec.gc.ca/soer-ree/English/products/factsheets/94-1.cfm

Evans K, Hindell MA, Thiele D. 2003. Body fat condition in sperm whales, Pyester macrophalus, from southern Australian water. Comparative Biochemistry and Biology Part $A$ 134:847-862.

Fast, H and Berkes, F. 1998. Climate change, northern subsistence and land-based economies. In: Mayer, N, ans Avis, W (editors). Canada country study: climate impacts and adaptation. Vol. 8: National cross-cutting issues. Ottawa: Environmenta Canada: 206-226.

Ferguson MAD, Messier F. Collection and analysis of traditional ecological knowledge about a population of Arctic tundra caribou. 1997. Arctic 50(1): 17-28.

Ferguson SH, Stirling I, McLoughlin P. 2005. Climate change and ringed seal (Phoca hispida) recruitment in western Hudson Bay. Marine Mammal Science 21(1):125135.

Finley KJ, Bradstreet MSW, Miller GW. Summer feeding ecology of harp seals (Phoca groenladica) in relation to Arctic cod (Boreogadus saida).1990. Polar Biology. 10:609-618.

Freeman, M.M.F. 1993. The International Whaling Commission, small-type whaling, and coming to terms with subsistence. Human Organization 52: 243-251.

Folke, C, Carpenter, S, Elmqvist. Resilience for sustainable development: building adaptive capacity in a world of transformations. International Council for Scientific Unions (ICSU), Rainbow Series, No.3, Paris. http://www.sou.gov.se/mvb/pdf/resiliens.pdf.

Fox, S. 1998. Inuit knowledge of climate and climate change. Unpublished Master's thesis. Waterloo, Ontario: Department of Geography, University of Waterloo. 
Fox, S. 2000. Arctic climate change: observations of Inuit in the eastern Canadian Arctic. In: Fetterer, F and Radionov, V (editors). Arctic Climatology Project, Environmental Working Group Arctic meteorology and climate atlas. Boulder, CO: National Snow and Ice Data Centre. CD-ROM.

Fox, S. 2002. These are thing that are really happening: Inuit perspectives on the evidence and impacts of climate change in Nunavut. In: Krupnik, I., and Jolly, D (eds). The Earth is Faster Now: Indigenous Observations of Arctic Environmental Change. Vol. Fairbanks, Alaska: Arctic Research Consortium of the United States.

Furgal, CM, Martin, D, and Gosselin, P. 2002. Climate change and health in Nunavik and Labrador. In: Krupnik, I., and Jolly, D (eds). The Earth is Faster Now: Indigenous Observations of Arctic Environmental Change. Vol. Fairbanks, Alaska: Arctic Research Consortium of the United States.

Gesler, W. 1992. Therapeutic landscapes: medical issues in light of the new cultural geography. Health \& Place 7: 735-746.

Gesler, W. 1996. Lourdes: healing in a place of pilgrimage. Health \& Place 2:95-105.

Grenier, Louise. Working with indigenous knowledge: a guide for researchers. International Development Research Center. Ottawa, Ontario, Canada. 1998. Pgs $1-11 ; 47-55$.

Greenwood, Davydd J., William F. Whyte, and Ira Harkavy. 1993. Participatory action research as a process and as a goal. Human Relations 46, 175-192.

Hammill, M.O. and Smith, T.G. 1989. Factors affecting the distribution and abundance of ringed seal structure in Barrow Strait, Northwest Territories. Canadian Journal or Zoology 67, 2212-2219.

Harwood, LA, and Stirling, I. 1992. Distribution of ringed seals in the southeastern Beaufort Sea during late summer. Canadian Journal of Zoology 70: 891-900.

Harwood, L.A., Smith, T.G., and Melling, H. 2000. Variation in reprodcution and body condition of the ringed seal (phoca hispida) in Western Prince Albert Sound, NT, Canada. Arctic 53, no. 4:422-431.

Harwood J. 2001. Marime mammals and their environment in the twenty-first century. Journal of Mammology 82(3): 630-640.

Huntington, HP. Observations on the utility of the semi-directive interview for 
documenting traditional ecological knowledge. 1998. Arctic 51(3):237-242

INAC 2006 http://www.ainc-inac.gc.ca/nin/pro/nvt/capedorset_e.html

Lockyer CH, McConnell, Waters TD. Body condition in terms of anatomical and biochemical assessment of body fats in North Atlantic fin and sei whales.1985. Canadian Journal of Zoology 63: 2328-2338.

Lonne OJ, Gulliksen B. 1989. Size, age and diet of polar cod, Boreogadus saida, in ice covered waters. Polar Biology 9:187-191.

Lyver POB, Lester KE, Dene First Nation. Monitoring barren-ground caribou body condition with Dene traditional knowledge. March 2005. Arctic 58(1): 44-54.

Ingold, T and Kurtilla, T. 2000. Perceiving the environment in Finnish Lapland. Body and Society 6(3): 187-200.

Intergovernmental Panel on Climate Change. 2001. Working Group I: The Scientific Basis. http://www.grida.no/climate/ipcc tar/wg1/index.htm

Intergovernmental Panel on Climate Change $3^{\text {rd }}$ Assessment Report (TAR) Working Group II. See: http://www.grida.no/climate/ipcc tar/wg2/index.htm.

Intergovernmental Panel on Climate Change. 2007. The Physical Science Basis: Summary for Policy Makers. http:/www.ipcc.ch/SPM2feb07.pdf

Johnson, Martha. 1992. Lore: capturing traditional environmental knowledge. International Development Research Center. Ottawa, Ontario, Canada. Pgs 3-19.

Kofinas, G, with the communities of aklavik, Arctic Village, Old Crow and Fort McPherson. 2002. Community contribution to ecological monitoring: Knowledge co-production in the U.S.-Canada Arctic Borderlands. In: Krupnik, I., and Jolly, D (eds). The Earth is Faster Now: Indigenous Observations of Arctic Environmental Change. Vol. Fairbanks, Alaska: Arctic Research Consortium of the United States.

Kristofferson, $\mathrm{AH}$ and Berkes, F. Adaptive co-management of Arctic char in Nunavut territory. In: Berkes, F, Huebert, R, Fast, H, Manseau, M, and Diduck, A (editors). Breaking ice: renewable resource and ocean management in the Canadian north. Vol. 7. Calgary: University of Calgary Press.

Kuhnlein, H.V., and Chan, H.M. 2000. Environment and contaminants in traditional food systems of northern indigenous peoples. Annual Review of Nutrition 20, 595-626. 
Krupnik, I., and Jolly, D (eds). 2002. The Earth is Faster Now: Indigenous Observations of Arctic Environmental Change. Vol. Fairbanks, Alaska: Arctic Research Consortium of the United States.

Mailhot, Jose. 1993. Traditional ecological knowledge: the diversity of knowledge systems and their study. Federal Environmental Assessment Panel. Quebec, Canada. Pg 10-23.

Manabe S, Spelman MJ and Stouffer RJ. Transient Responses of a Coupled OceanAtmosphere Model to gradual Changes of Atmospheric CO2. Part I: Annual Mean Response. Journal of Climate. 5: 105-126.

McLaren IA, Smith TG. 1985. Population ecology of seals: retrospective and prospective views. Marine Mammal Science 1: 54-83.

McDonald, M., Arrautainaq, L., and Novalinga, Z. 1997. Voices from the bay: traditional ecological knowledge of Inuit and Cree in the Hudson Bay bioregion. Ottawa: Canadian Arctic Resources Committee and Sanikiluaq, NWT.

Myers, H, Fast, H, Berkes, MK, and Berkes, F. 2005. Feeding the family in times of crisis. In: Berkes, F, Huebert, R, Fast, H, Manseau, M, and Diduck, A (editors). Breaking ice: renewable resource and ocean management in the Canadian north. Vol. 7. Calgary: University of Calgary Press.

Nichols T, Berkes F, Jolly D, Snow NB, The Community of Sachs Harbour. 2004. Climate change and sea ice: local observations from the Canadian western Arctic. Arctic 57(1): 68-79.

Parkinson, CL. 2000. Variability of Arctic sea ice: The view from space, an 18-year record. Arctic 53: 341-358.

Parlee, B, Manseau, M, and Lustel Ke' Dene First Nation. 2005. Understanding and communicating about ecological change: Denesoline indicators of ecosystem health. In: Berkes, F, Huebert, R, Fast, H, Manseau, M, and Diduck, A (editors). Breaking ice: renewable resource and ocean management in the Canadian north. Vol. 7. Calgary: University of Calgary Press.

Peter, A, Ishulutak, M, Shaimaiyuk, J, Shaimaiyuk, J, Kisa, N, Kootoo, B, Enuaraq, S. 2002. Seal: An integral part of our culture. Etudes Inuit/Studies 26(1): 167-174.

Poirier S, Brooke L. Inuit perceptions of contaminants and environmental knowledge in Salluit, Nunavik. 2000. Arctic Anthropology 37(2):78-91.

Reidlinger, D. Master's thesis. 2001. Community-based assessments of change: 
contributions of Inuvialuit knowledge to understanding climate change in the Canadian Arctic. Natural Resources Institute. University of Manitoba.

Riedlinger D, Berkes F. 2001 Contributions of traditional knowledge to understanding climate change in the Canadian Arctic. Polar Record 37(203): 315-328.

Serreze, MC, Walsh, JE, Chapin, FS, Osterkamp, T, Dyurgerov, M, Romanovsky, V, Oechel, WC, Morison, J, Zhang, T, and Barry, RG. 2000. Observational evidence of recent change in the northern high-latitude environment. Climate Change 46: 159207.

Serreze, M. C., M. M. Holland, and J. Stroeve. 2007. Perspectives on the Arctic's shrinking sea-ice cover. Science (New York, N.Y.) 315, no. 5818:1533-1536.

Smith TG, Hammill MO, Taugbol G. 1991. A review of the development, behavioural and physiological adaptations of the ringed seal (Phoca hispida) to life in the Arctic winter. Arctic 44: 124-131.

Stirling, I. 1997. The importance of polynyas, ice edges, and leads to marine mammals and birds. Journal of Marine Systems 10: 9-21.

Stirling I, Smith TG. 2004. Implications of warm temperatures and an unusual rain event for the survival of ringed seal (Phoca hispida) on the coast of southeastern baffin island. Arctic 57(1): 59-67.

Szathmary, EJE, Ritenbaugh, C, Goodby, CSM. 1987. Dietary change and plasma glucose levels in an Amerindian population undergoing cultural transition. Social Science and Medicine 24(10):791-804.

Tesch R. Qualitative research: analysis types and software tools. New York: Falmer.

Thorpe NL. 1997. The tuktu and nogak project: Inuit knowledge about caribou and calving areas in the Bathurst inlet region. Arctic 50(4): 381-384.

Thorpe, NL. 2000. Contributions of Inuit ecological knowledge to understanding the impacts of climate change on the Bathurst caribou herb in the Kitikmeot region, Nunavut. Thesis (M.R.M), Simon Fraser University.

Thompson, S. 2005. Aboriginal Arctic food security in a toxic world. In: Berkes, F, Huebert, R, Fast, H, Manseau, M, and Diduck, A (editors). Breaking ice: renewable resource and ocean management in the Canadian north. Vol. 7. Calgary: University of Calgary Press. 
Thouez, JP, Rannou, A, and Foggin, P. 1989. The other face of development: Native population, health status, and indicators of malnutrition-the case of the Cree and Inuit of Northern Quebec. Social Science and Medicine 29(8): 965-74.

Tynan CT, DeMaster DP. 1997. Observations and predictions of Arctic climatic change: potential effects on marine mammals. 50(4): 308-322.

Usher, P, Baikie, M, Demmer, M, Nashima, D, Stevenson, MG, and Stiles, M. 1995. Communicating about contaminants in country food: experience in Aboriginal communities. Ottawa: Inuit Tapirisat of Canada.

Usher PJ. 2000. Traditional ecological knowledge in environmental assessment and management. Arctic 53(2): 183-193.

Usher, P. J. 2002. Inuvialuit use of the Beaufort Sea and its resources, 1966-2000. Arctic 55, no. Supp.1.:18-28.

Usher, P., Duhaine, G and Searles, E. 2003. The household as an economic unit in Arctic Aboriginal communities, and its measurement by means of a comprehensive survey. Social Indicator Research 61: 175-202.

Vinnikov, K. Y., et al. 1999. Global Warming and Northern Hemisphere Sea Ice Extent. Science 286, no. 5446:1934-1937.

Wakefield, S., and McMullan, C. 2005. Healing in places of decline: (re)imaging everyday landscapes in Hamilton, Ontario. Health \& Place 11: 299-312.

Wenzel GW. 2004. From TEK to IQ: Inuit Qaujimajatuqangit and Inuit cultural ecology. Arctic Anthropology. 41(2): 238-250.

Whalter, GR, Burga, CA, and Edwards, PJ (editors). 2001. "Fingerprints" of climate change: adapted behaviour and shifting species ranges. New York: Kluwer Academic/Plenum Publishers.

Whyte, William F., Davydd J. Greenwood, and Peter Lazes. 1989. Participatory action research: through practice to science in social research. The American Behavioral Scientist 32: 513-551.

Whyte, W.F. ed. 1991. Participatory action research. Newbury Park: Sage Publications.

Wilson, K. 2003. Therapeutic landscapes and First Nations peoples: an exploration of culture, health and place. Health \& Place 9: 83-93. 
World Health Organization. The Preamble to the Constitution of the World Health Organization as adopted by the International Health Conference, New York, 19 June-22 July 1946.

http://www.who.int/library/historical/access/who/index.en.shtml

Zamparo, JoAnne. 1996. Informing the facts:Inuit traditional knowledge contributes another perspective. Geoscience Canada 23 (4): 261-266. 


\section{Appendix A}

\section{Community-based Monitoring of Ringed Seal in Cape Dorset, Nunavut}

Part of the goal of my master's thesis when I first began was to participate in the development of a small-scale community-based monitoring program to begin gathering baseline data that could be used to follow the health of ringed seals in Cape Dorset, Nunavut. My interest in community-based research stemmed from my belief in collaborative research and a deep desire to partner and work with the community in as many stages of the research process as possible. Given that this was my first experiencing working with a community to develop a monitoring program, I knew that the outcome would be unknown. The emphasis of the project was more focused on the process of developing a joint venture with the community of Cape Dorset. I had received positive input about the project from my supervisor and peers and funding agencies, which supported the project as being well-planned and scientifically sound. Most importantly, however, was the support that I received from the community of Cape Dorset, who believed that the research was significant and worthwhile.

The beginning stages of the project were exciting and successful. I had received a letter of support from the Hunters and Trappers Association welcoming my research into the community. I had received ethics approval from Carleton University, and successfully applied for a research licence from the Nunavut Research Institute. I had secured enough funding to support two seal hunters, and to purchase research supplies for the project. A great deal of preparation went into the planning and organization of the project. I wanted to be able to present my community partners with all the information and tools I could gather regarding ringed seal health, in order to contribute resources and information to 
the development of the project. Supplies and procedure manuals were prepared before going to Cape Dorset. While there were specific measurements to be taken, the project also relied on the hunters' knowledge and expertise of seal health. It is for this reason that in addition to numerical measurements, seal monitors were asked to provide detailed descriptions of their overall assessments of the health of harvested seals, and include any other information that they found to be relevant.

Once I arrived in Cape Dorset, I spoke to many hunters about the monitoring program, and the need for community partners to collaborate with. I was able to find two very interested hunters, that were concerned about ringed seals in the area and believed monitoring ringed seals and establishing baseline data was important for the community. The hunters were given all the equipment that they would need to collect data, such as notebooks, pens, measuring tape, cameras, etc. During our meetings we established the period of time during which sampling would take place. The hunters felt that the best seal hunting occurs during the fall and winters months, and that this would be the best time to sample seals. Sampling would take place for a 5 to 6 month period (September to February) starting shortly after I left the community. Unfortunately, I did not have the resources to remain in the community for the 5 to 6 month period. In addition, I had to return to Ottawa to complete two courses during the fall semester. Even though I would be leaving the community, I had already learned so much about conducting communitybased research. It was an enlightening experience to be able to share information, to brainstorm ideas and to work closely with hunters that had so much experience and knowledge. 
As I had mentioned earlier, I was less concerned with the results of the monitoring program as I was interested in the process of developing a collaborative working relationship with the extremely capable hunters I had met in Cape Dorset. While the hunters had made attempts to collect the monitoring data, the weather had been extremely unfavourable this year, and as a result they rarely went seall hunting. When they did go hunting, they did not catch any seals, and therefore no measurements could be taken. Despite the lack of data collection, the monitoring portion of the project had many successes. There are certain things that are out of our control, the weather being one of them. The fact that it was not possible for data to be collected this year does nothing to diminish the possibility of data being collected in the future. If anything, this experience is part of the process of developing a community-based monitoring program, and because it has taught us something, in its own way it is a success. This joint venture was a process that allowed me to develop a close and collaborative relationship with many members of the community of Cape Dorset. I learned that one of the most important aspects of conducting community-based research is finding common ground between the interests of the community and the interests of the researcher. I have also learned to be open and flexible to the research process itself. I am still a strong believer in collaborative, community-based research. Community-based monitoring programs can bridge the gap between scientists and northern communities, and enable local input to be included in the monitoring of environmental variables.

The most important thing that I take away with me from this experience is the relationships that I have developed with many residents of Cape Dorset. The friends and collaborators I have made have taught me about what life in the North is really like, and 
have forever changed my outlook on life and on research. I look forward to continuing my personal and academic relationship with the people Cape Dorset during my doctoral studies and beyond. 


\title{
Appendix B
}

\section{Ethics Proposal and Interview Guide}

General Application for Ethics Review

\section{Monitoring Ringed seal (Phoca hispida) Body Condition Using Conventional Methods and Traditional Knowledge in Cape Dorset, Nunavut.}

\section{Ethics Proposal}

\author{
Anita Kushwaha \\ (100311712)
Department of Geography and Environmental Studies
Carleton University \\ Supervisor: \\ Dr. Nancy C. Doubleday \\ Submitted to: \\ Carleton University Research Ethics Committee
}

June 2006 


\section{APPLICANT AND PROTOCOL INFORMATION FORM}

See attached form

\section{LAY WORD SUMMARY}

Climate change in the polar region is expected to be among the greatest of any region on Earth. A warmer northern climate will result in less sea ice and fewer ice edges, which are prime habitats for marine organisms such as seal, walrus, and polar bear. Habitat loss is expected to negatively impact the reproductive success of marine mammals. The goal of this study is to use a combination of traditional knowledge and biological measurements in order to holistically monitor the body condition and health of ringed seals (Phoca hispida) in Cape Dorset, Nunavut, Canada. The objectives of the study are to:

1) Document traditional knowledge regarding the effects of climate change on sea ice and ringed seals in order to construct climate history and baseline data for the area;

2) By the method of community-based monitoring, establish baseline data for ringed seal body condition that can serve in long-term monitoring;

3) Attempt to relate ringed seal body condition data to historical climate data for the area; and

4) Contribute to the development of cross-cultural dialogue and collaboration on the issue of climate change and marine mammal health.

\section{METHODOLOGY AND PROCEDURES}

This research will be conducted following a participatory action research (PAR) methodology. The community has been consulted about the project and has given their support to this wild life health study (as indicated by letter of support). As stated previously, one of the main objectives of this proposed study is to establish baseline body 
condition data that can be used in the long term monitoring of seals in Cape Dorset, Nunavut. This will be achieved through a community-based, participatory approach. Local hunters (or "seal monitors") will measure and collect seal samples during regular hunts. It is difficult to estimate the number of seals that will be harvested and available for sampling, but I hope to acquire 50 to 100 samples. The following information will be collected from each seal harvested: date, location of kill, sex, the monitor's assessment of relative age and the monitor's assessment of overall body condition will be analyzed based on blubber thickness measurements. If possible, I would also like to provide the seal monitors with a Polaroid camera, in order to visually document the body condition of the ringed seals used in the study. The photographs will be used in conjunction with the seal monitor's overall assessment of the seal's condition. One photograph would be taken for each seal before butchering to see the external condition of the animal, and postbutchering to see the internal condition (specifically that of the blubber layer). I hope to then use the photographs to develop a scorecard that estimates ringed seal body condition based on external and internal visual cues.

The second portion of the study involves documenting traditional ecological knowledge (TEK). TEK will be collected by method of semi-directed (or open-ended) interviews. TEK will be documented using a combination of interview transcription and (if the participants are comfortable with) audio tape recording. This will ensure that the interviews are recorded as completely and accurately as possible. This will aid greatly during the analysis portion of the study. I anticipate conducting approximately 30 interviews ( 15 men, 15 women) with community members. The interviews will be conducted in English and Inuktitut, with the aid of an interpreter, with whom I have 
worked previously. The majority of the interviews will be conducted in the community Visitors Centre. Exceptions will be made, however, in the case of interviews with Elders who may want to be interviewed in their homes.

\section{DECEPTION N/A}

\section{DESCRIPTION OF PARTICIPANTS}

I anticipate conducting approximately 30 interviews (15 men, 15 women) with community members. The participants will be chosen strategically. Considering the nature of the study and the need for rather specific information regarding seal body condition, the community members that will be approached are those who have extensive knowledge in the hunting and preparation of seals. I estimate that the average age of participants will range from 30 to 60 years. This decision regarding age was made due to my particular interest in the knowledge of Elders, who although they may no longer hunt regularly, will likely still have valuable insights regarding environmental change.

\section{SPECIAL CONSIDERATIONS: MARGINALIZED GROUPS}

This research depends on the involvement of the predominately Inuit community of Cape Dorset, Nunavut. Within the past year I have travelled and worked in the community on two separate occasions. During my first trip I worked as a research assistant. My task was to conduct interviews with women in the community as part of a land and health study. During my second trip in March 2006, I helped to co-ordinate a workshop about research and proposal writing. While in the community I have taken advantage of each opportunity to expand my knowledge 
of Inuit culture and way of life. I have spent time out on the land with community members and participated in traditional activities such as clam digging, berry picking and seal hunting. I have also engaged in many meaningful discussions with community members that have helped me gain a greater appreciation for the Inuit perspective.

\section{LANGUAGE BARRIERS}

I am aware that in certain circumstances language barriers may present themselves. For example, when interviewing Elders, who may be more comfortable speaking in Inuktitut than in English. It is for this reason that every interview will be conducted in the presence if an Inuktitut speaking interpreter. This precaution will ensure that each participant will be able to express him/herself in whichever language they are most comfortable. In addition, the letter of consent will be translated in Inuktitut for the participants to read, so there are no miscommunications with regards to the purpose of the study and the rights of the participants.

\section{RECRUITMENT PROCESS}

I will require the assistance of my interpreter in order to recruit participants. As a former mayor and prominent figure, she is well-connected throughout the community and will be able to help identify which community members would have the greatest knowledge regarding climate change, sea ice and ringed seal body condition. This method of recruitment has been applied on previous projects that I have assisted with in 
Cape Dorset with great success. There will be no recruitment advertisement distributed in the community. But rather, potential participants (i.e. that have knowledge about sea ice, climate change and ringed seal body condition) will be contacted by telephone or in person and informed about the study. If the individuals express interest in participating an interview will be arranged at a suitable time. The majority of interviews will be conducted in the Visitor Centre, which is located in the centre of the community. The facilities are a safe, neutral place to conduct interviews. Special arrangements will be made for participants who do not feel comfortable leaving their homes, such as Elders. I plan to offer modest honoraria (i.e. twenty dollars cash) to the participants as a sign of appreciation for the time they donate to the study. The honoraria will be discretely presented to each participant after the interview has been conducted along with a receipt.

\section{RISKS}

There are no apparent risks to the participants involved in this study. The interview topics are focused around climate change, sea ice integrity and ringed seal body condition. The topics are not intended to be of a personal nature but rather are directed at surrounding environmental changes and land use. I foresee that minor emotional stress may occur for participants that "reminisce" about how the environment used to be, or that discuss what they fear may happen to the environment in the future. I have no intention of pressuring participants to discuss any topics that make them uncomfortable. The participants will always have the option of not discussing topics that make them uneasy. 


\section{BENEFITS}

This project has the potential to benefit the community in several ways. The participants will be able to express their concerns regarding climate change and how this is impacting their lives and livelihoods. They will also be actively participating in a community-based project that will establish baseline data for ringed seal body condition that may be used in long term studies. This has the potential to spark interest and community involvement in environmental and research activities. The community will also benefit from the project deliverables such as a written copy of the final thesis submitted to the municipality of Cape Dorset for public viewing, and scorecards that may be used for future monitoring.

\section{ANONYMITY OF PARTICIPANTS}

I will be offering the participants anonymity in the final thesis only. Since the community of Cape Dorset is so small, it will be too difficult (or even impossible) to offer anonymity in the field. They will have the choice of whether or not to be identified in the final report. If they chose to be identified, they will be thanked in the acknowledgements section of the thesis only. If the participants prefer to remain anonymous their name will not appear anywhere in the thesis. No quotes used in the thesis will be marked by names, but rather by impersonal identifiers such as "Inuit Elder" or "Inuit hunter". 


\section{CONFIDENTIALITY}

I will ensure the participants that whatever they tell me during the interviews is confidential, and will not be discussed with anyone not involved in the study. I will also ensure the participants that the data from the interviews will not be shared with other researchers or used for a project other than the original project it was intended for. In order to keep the interviews confidential, they will be identified in notebooks and tape recordings by date and time only. In addition, since I am offering anonymity in the final thesis, no quotes used in the thesis will be marked by names, but rather by impersonal identifiers such as "Inuit Elder" or "Inuit hunter". However, the participants will have the option of having their participation acknowledged in the acknowledgement section of the thesis (see informed consent letter).

\section{SECURITY OF DATA}

In order to ensure the security of the data, the notebooks and tape recordings used to document the interviews and the consent forms, will be stored in a locked filing cabinet, located in my home office in my place of residence. The benefit of keeping the data secure at my own residence is that I am the only person that has access to the office, and the only person with a key to open the filing cabinet. The notebooks and tape recordings will be stored in the locked filing cabinet for the length of the study. Once the study is completed the data will be permanently stored in the locked filing cabinet. 


\section{DESTRUCTION OF DATA}

I do not intend to dispose of the notebooks and tape recordings used to document interviews in the study. I intend to always keep the data in a safe and secure location (i.e. in a safety box under lock and key) to ensure that I remain the only person that has access to the data.

\section{FUTURE USE OF DATA}

The data used in the study will be used to write my final thesis. In addition, the study will be submitted to journals for publication if possible. I may also present the data at conferences. Since part of the study attempts to establish baseline data, it is presumed that the ringed seal body condition data collected may be used in future studies.

\section{SHARING DATA/OTHER USES}

The data collected will not shared with other researchers or used for a project other than the original project it was intended for. If I require use of the data in the future, in some way that I cannot foresee at the moment, I will contact the participants and ask their consent to do so.

\section{LETTER OF INFORMATION}

See attached

\section{INFORMED CONSENT FORM}

See attached combined letter and consent form 


\section{RESEARCH INSTRUMENT}

See attached interview guide/questionnaire

\section{PHOTOGRAPHS}

The only photographs taken in the study will be those of harvested ringed seals. No human participants will be photographed without consent.

\section{AUDIO/VIDEO RECORDINGS}

The interviews will be tape recorded only if consent is given by the participants. While this is my preference in order to fully document the interviews, I will not under any circumstances tape record the interview against the wishes of the participants.

\section{DISSEMINATION}

I intend to present my research findings in a final written thesis that will be accessible at the Carleton University library. I also hope to submit and publish the research findings as journal articles. I may also present my findings at conferences and in class room presentations to my peers. 


\section{Interview Guide/Questionnaire For M.Sc. Research on: Monitoring ringed seal (Phoca hispida) bodv condition using conventional methods and traditional knowledge. \\ By: Anita Kushwaha}

\section{Topic 1. Sea Ice Conditions}

- Have you noticed any changes in sea ice conditions? If so, what and where?

- Has the sea ice been melting earlier in recent year? If so, when (i.e. what month)?

- Is the sea ice thinner than it used to be? If so, where?

- Do you trust the sea ice? Are there times when you don't? Are there areas you now avoid when hunting because you cannot trust the ice (i.e. not safe)?

\section{Topic 2. Seasons}

- Have you noticed changes in the sea ice breakup dates?

- Have you noticed changes in the freeze up dates?

- When do breakup and freeze up normally occur?

- Have you noticed any changes in the seasons? (e.g. changes in rainfall or temperature)

- How often does it storm?

- Are rainstorms becoming more or less common?

\section{Topic 3. Hunting and Seal Condition}

- What are ideal conditions for seal hunting?

- Where do you travel across the sea ice to hunt for seals? How do you travel there?

- Has the timing of the hunt changed? If so, how and what else as changed about the hunt?

- Have you noticed any changes in the health of seals? In the number of seals?*

- How can you tell a seal is fit for consumption? What external/internal signs?

- Are the seals skinnier?

- Have you noticed any changes in the condition (appearance, smell, texture, taste) of the seal blubber?

- Are seals harder to hunt these days? If so, why?

\section{Topic 4. Climate Change}

- Do you think the climate has changed since you were a child? If so, how?

- Do you have concerns about climate change? If so, what?

- Do you think climate change will have an effect on the health of seals?

- How do you think climate change will affect Inuit traditional activities (i.e. hunting, fishing)?

\footnotetext{
*This question was added to the interview guide while in Cape Dorset and did not appear in the original ethics application.
} 